Key Words:

Thermal Modeling, RF Ion Exchange Column, Heat Transfer Analysis

Retention:

Permanent

\title{
THERMAL MODELING OF ION EXCHANGE COLUMNS WITH SPHERICAL RF RESIN
}

DECEMBER 2009

Savannah River National Laboratory Savannah River Nuclear Solutions Aiken, SC 29808

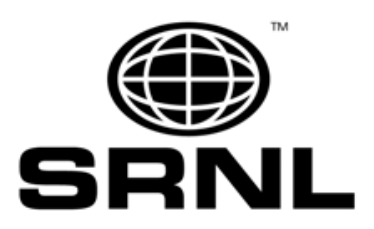


DISCLAIMER

This report has been authored by Savannah River Nuclear Solutions,
LLC under Contract No. DE-AC09-08SR22470 with the U.S.
Department of Energy. Specifically, the research was supported by a
Work for Others (WFO-08-014) with Washington Safety
Management Solutions LLC. The United States Government retains
and the publisher, by accepting this article for publication,
acknowledges that the United States Government retains a non-
exclusive, paid-up, irrevocable, worldwide license to publish or
reproduce the published form of this work, or allow others to do so, for
United States Government purposes.


Key Words:

Thermal Modeling, RF Ion Exchange Column, Heat Transfer Analysis

Retention:

Permanent

\section{THERMAL MODELING OF ION EXCHANGE COLUMNS WITH SPHERICAL RF RESIN}

Si Young Lee

William D. King

DECEMBER 2009

Savannah River National Laboratory

Savannah River Nuclear Solutions

Savannah River Site

Aiken, SC 29808 


\section{REVIEWS AND APPROVALS}

$\overline{\text { S. Y. Lee, Author, Applied Computational Engineering \& Statistics Group Date }}$

W. D. King, Coauthor, Adv. Characterization \& Process Group Date

$\overline{\text { F. G. Smith, III, Reviewer, Process Modeling \& Computational Chemistry Group Date }}$

$\overline{P .}$ L. Lee, Manager, Applied Computational Engineering \& Statistics Group Date

S. J. Hensel, Manager, Computational Engineering \& Sciences Section Date

F. M. Pennebaker, Manager, Adv. Characterization \& Process Group Date

W. R. Wilmarth, Manager, EM Tech. Integration Office

Date

D. H. Shuford, Customer, Hanford Representative

Date 


\section{TABLE OF CONTENTS}

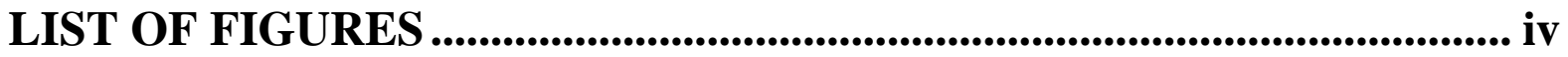

LIST OF TABLES ......................................................................................... vi

LIST OF ACRONYMS .............................................................................. vii

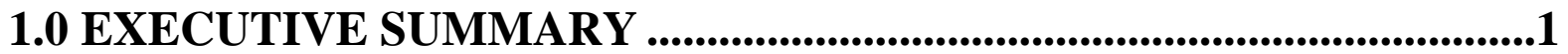

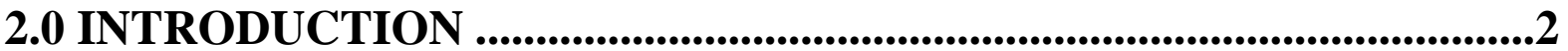

3.0 SOLUTION APPROACH AND MODELING ASSUMPTIONS .............3

4.0 MODELING RESULTS AND DISCUSSION .......................................17

4.1 BENCHMARKING RESULTS........................................................................................17

4.2 RESULTS FOR CASE 1..................................................................................................23

4.3 RESULTS FOR CASE 2 ..............................................................................................26

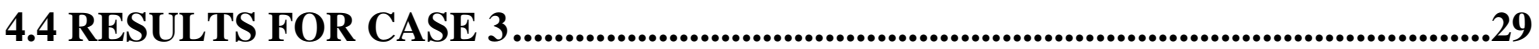

5.0 CONCLUSIONS AND SUMMARY ..........................................................42

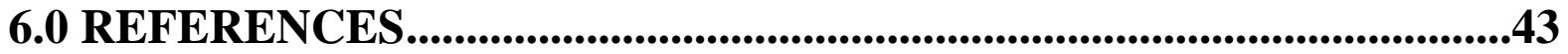




\section{LIST OF FIGURES}

Figure 1. Typical temperature profiles of packed columns under mixed convection cooling modes and no flow conditions

Figure 2. Three SCIX baseline modeling conditions considered for the analysis. 5

Figure 3. Natural convection heat transfer correlation available in the literature showing the conservatism imbedded in the present heat transfer analysis.

Figure 4. Forced convection correlation available in the literature demonstrating the range of the convective heat transfer through the water cooling system of the SCIX column.

Figure 5. Sensitivity results associated with numerical energy residual showing that about 8,100 meshes are established for the present analysis ................................ 16

Figure 6. Computational nodes for the two-dimensional computational domain of the 28-in column (8,100 nodes).....

Figure 7. Graphical illustration of the heat transfer model of the RF column under natural convection cooling for the benchmarking analysis.

Figure 8. Comparison of steady state results between the numerical predictions and theoretical results for the cylindrical column with $133.49 \mathrm{Ci} /$ liter heat load for the model benchmarking.

Figure 9. Temperature distributions for a 32 -in diameter RF column with $100 \%$ cesium loading (Case 1)

Figure 10. Max. column temperatures vs. column diameters under three different cesium loadings (Case 1)

Figure 11. Comparison of max. column temperatures for two different ambient air temperatures, $35^{\circ} \mathrm{C}$ and $45^{\circ} \mathrm{C}$, at $100 \%$ cesium loading (Case 1 ).

Figure 12. Comparison of temperature distributions for the 28in OD columns with 4 external cooling tubes (Case 2) and without cooling tubes (Case 1)

Figure 13. Comparison of radial temperature distributions for the 28-in RF column between Case 1 and Case 2

Figure 14. Comparison of maximum temperatures between case 1 and Case 2 .....

Figure 15. Percentage ratio of forced convective cooling area to total exterior column wall surface area versus column diameter

Figure 16. Comparison of transient maximum temperatures for three different column diameters under Case 3 (air-filled, water-cooled) conditions 
Figure 17. Comparison of temperature distributions for the dry columns filled with $43.2 \%$ and $36.0 \%$ porosities (Case 3 ) for the 28 in OD columns with 4 external cooling tubes at the transient time of 12 hours

Figure 18. Comparison of transient maximum temperatures for three different column porosities under the 28-in column under Case 3 (air-filled, water cooled) conditions.

Figure 19. Comparison of radial temperature distributions for three different column porosities after 12 hours for the 28 -in column under Case 3 conditions.

Figure 20. Comparison of maximum temperatures between $50 \%$ and $100 \%$ Cs loading levels for the 28 in under Case 3 (air-filled, water-cooled) conditions.

Figure 21. Comparison of transient maximum temperatures between the columns with and without external four cooling tubes under Case 3 conditions but with only $50 \%$ Cs loading.

Figure 22. Comparison of radial temperature contours between the columns with and without four external cooling tubes at a transient time of 26 hours (50\% Cs loading).

Figure 23. Comparison of radial temperature distributions along the line A-A' between the columns with and without external four cooling tubes at transient time of 26 hours (50\% Cs loading).....

Figure 24. Comparison of steady-state temperature contours between the 28-in baseline columns with and without 6 -in central cooling tube under the Case- 3 conditions 40

Figure 25. Comparison of transient max. temperatures between the columns with and without 6 -in central cooling pipe under the 28-in fully-loaded dry column with four external cooling tubes 


\section{LIST OF TABLES}

Table 1. Baseline modeling conditions used for the present heat transfer analysis of the SCIX column.

Table 2. Three baseline cases considered for the two-dimensional transient calculations under the column fully loaded with radioactive cesium

Table 3. Heat source terms for the 28-in baseline RF column used for the present study 13

Table 4. Material and thermal properties for heat transfer calculations of the RF column 15

Table 5. Three regions used for the benchmarking analysis against the computational model

Table 6. Quantitative comparison between theoretical and modeling results for two different RF column sizes

Table 7. Quantitative comparison of the RF column sizes to satisfy the operation and safety limits under three different cesium loadings with $45^{\circ} \mathrm{C}$ ambient air temperature.

Table 8. Quantitative comparison of RF column sizes to satisfy the operation and safety limits under two different ambient air temperatures at 100\% cesium loading ....25

Table 9. Quantitative comparison of column sizes to satisfy the safety and operation limits between Case 1 and Case 2 .

Table 10. Quantitative comparison of transient response times to reach the safety and operational temperature limits for various column diameters under Case 3......32

Table 11. Quantitative comparison of transient response times to reach the safety and operational temperature limits for three different bed porosities under Case 3 conditions with a 28 inch column.

Table 12. Quantitative comparison of Cs loading levels on transient response times for a 28 inch column to reach the safety and operational temperature limits under Case 3 conditions. 36

Table 13. Quantitative comparison of the impact of external cooling tubes on the transient response times to reach the safety and operational temperature limits under Case 3 conditions for the 28 inch column with $50 \%$ loading.

Table 14. Quantitative comparison of maximum steady-state temperature for all three cases with 28-in fully-loaded column.

Table 15. Quantitative comparison of the impact of 6-in central cooling tube on the transient response times to reach the safety and operational temperature limits under Case 3 conditions for the 28 inch column with 100\% loading. 


\section{LIST OF ACRONYMS}

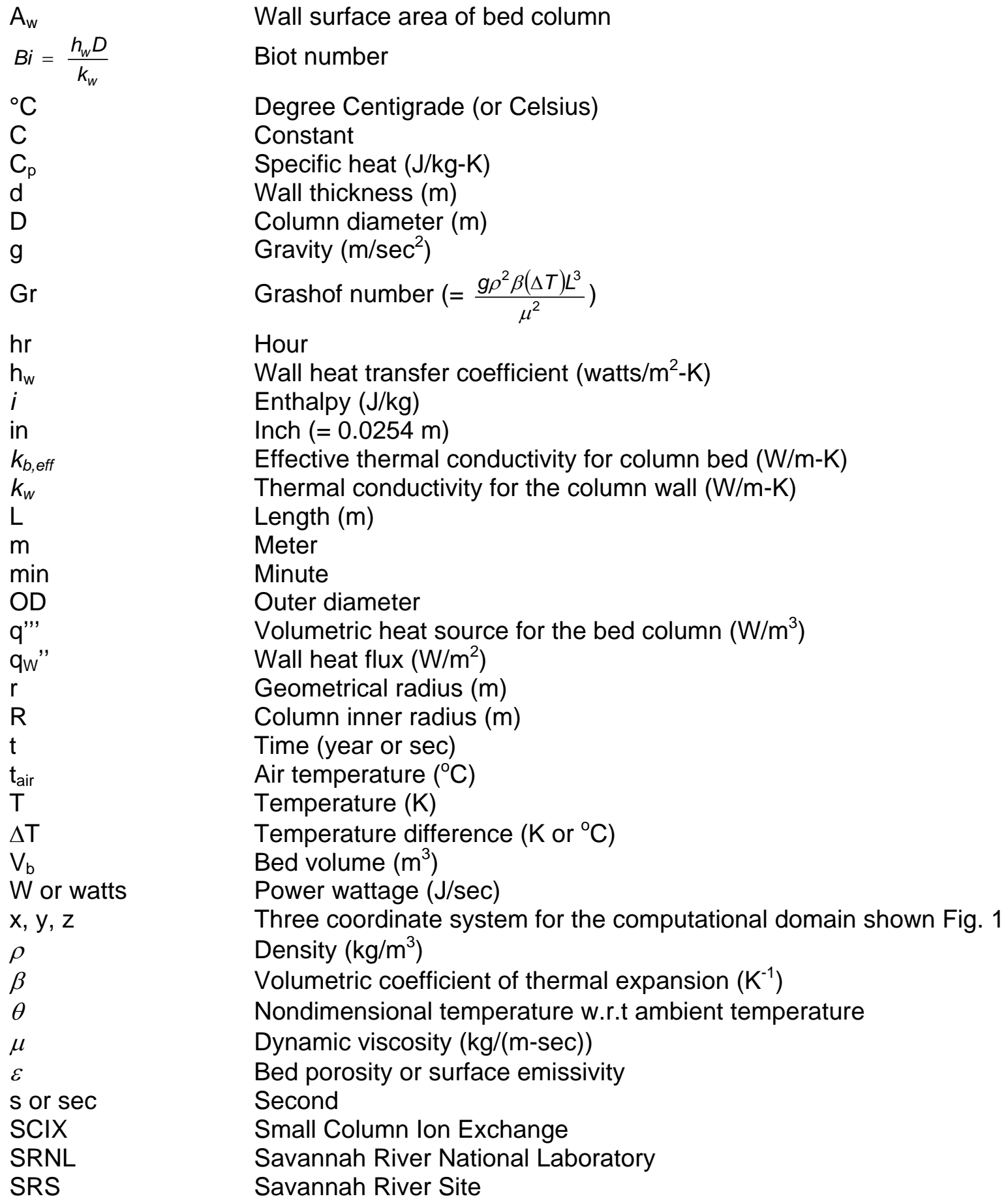




\subsection{EXECUTIVE SUMMARY}

Models have been developed to simulate the thermal performance of RF columns fully loaded with radioactive cesium. Temperature distributions and maximum temperatures across the column were calculated during Small Column Ion Exchange (SCIX) process upset conditions with a focus on implementation at Hanford. A two-dimensional computational modeling approach was taken to include conservative, bounding estimates for key parameters such that the results will provide the maximum centerline temperatures achievable under the design configurations using a feed composition known to promote high cesium loading on RF. The current full-scale design for the SCIX system includes a central cooling tube, and one objective of these calculations was to examine its elimination to simplify the design. Results confirmed that a column design without a central cooling tube is feasible for RF, allowing for the possibility of significant design simplifications if it can be assumed that the columns are always filled with liquid. With active cooling through the four outer tubes, the maximum column diameter expected to maintain the temperature below the assumed media and safety limits is 26 inches, which is comparable to the current design diameter.

Additional analysis was conducted to predict the maximum column temperatures for the previously unevaluated accident scenario involving inadvertent drainage of liquid from a cesium-saturated column, with retention of the ion exchange media and cesium in the column. As expected, much higher maximum temperatures are observed in this case due to the poor heat transfer properties of air versus liquid. For this hypothetical accident scenario involving inadvertent and complete drainage of liquid from a cesiumsaturated column, the modeling results indicate that the maximum temperature within a 28 inch diameter RF column with external cooling is expected to exceed $250^{\circ} \mathrm{C}$ within 2 days, while the maximum temperature of a 12 inch column is maintained below $100^{\circ} \mathrm{C}$. In addition, the calculation results demonstrate that the cooling tube system external to an air-filled column is not highly effective at reducing the maximum temperature, but the baseline design using a central cooling tube inside the column provides sufficient cooling to maintain the maximum temperature near the assumed safety limit. 


\subsection{INTRODUCTION}

The In-Riser Ion Exchange program focuses on the development of in-tank systems to decontaminate high level waste (HLW) salt solutions at the Savannah River Site (SRS) and the Hanford Site. Small Column Ion Exchange (SCIX) treatment for cesium removal is a primary in-riser technology for decontamination prior to final waste immobilization in Saltstone. Through this process, radioactive cesium from the salt solution is adsorbed onto the ion exchange media which is packed within a flow-through column. Spherical Resorcinol-Formaldehyde (RF) is being considered as the ion exchange media for the application of this technology at both sites.

A packed column loaded with media containing radioactive cesium generates significant heat from radiolytic decay. Under normal operating conditions, process fluid flow through the column can provide adequate heat removal from the columns. However, in the unexpected event of loss of fluid flow or fluid drainage from the column, the design must be adequate to handle the thermal load to avoid unacceptable temperature excursions. Otherwise, hot spots may develop locally which could degrade the performance of the ion-exchange media or the temperature could rise above column safety limits. Data exists which indicates that performance degradation with regard to cesium removal occurs with RF at $65^{\circ} \mathrm{C}$. In addition, the waste supernate solution will boil around $130^{\circ} \mathrm{C}$ [1]. As a result, two temperature limits have been assumed for this analysis. These limits were not developed based on any detailed systems evaluation, but were instead selected based on the data available at the time. An operating temperature limit of $65^{\circ} \mathrm{C}$ was selected as the preferred temperature limit during routine operations based on the belief that this was a conservative limit which would protect the RF media from thermal degradation. A safety temperature limit of $130^{\circ} \mathrm{C}$ was selected under the assumption that solution boiling could cause significant safety concerns. An additional upset scenario was considered involving the loss of the supernate solution due to inadvertent fluid drainage through the column boundary. In this case, the column containing the loaded media could be completely dry. This event is expected to result in high temperatures that could damage the column or cause the RF sorbent material to undergo undesired physical changes. One objective of these calculations is to determine the range of temperatures that should be evaluated during testing with the RF media. Although, the safety temperature limit is based on the salt solution boiling point which does not apply in the air-filled case (because there is no liquid), this same limit $\left(130^{\circ} \mathrm{C}\right)$ is used as a measure for the evaluation of this condition as well.

The primary objective of the present work is to develop models to simulate the thermal performance of the RF column design when the media is fully loaded with radioactive cesium and the central cooling tube is excluded. Previous analysis led to the consideration of this design simplification for RF, since the baseline column design with center cooling was developed assuming that CST media would be used for cesium removal which has a higher volumetric heat load [3]. Temperature distributions and maximum temperatures across the column during SCIX process operations and upset conditions were conducted with a focus on SCIX implementation at Hanford [2]. However, a feed composition and cesium loading were assumed which were known to be considerably higher than would typically be observed at Hanford. In order to evaluate the impact of this potentially highly conservative assumption, fractionally-reduced loading cases were also considered. A computational modeling approach was taken to include conservative, bounding estimates for key parameters so that the results would provide the maximum temperatures achievable under the design configurations. 


\subsection{SOLUTION APPROACH AND MODELING ASSUMPTIONS}

For the SCIX process, the baseline design involves a column bed from 10 to $25 \mathrm{ft}$ tall. A fully-loaded column may contain as much as $133 \mathrm{Ci} /$ liter of Cs-137 (maximum expected loading with RF, Refs. 4 to 6 ) based on the equilibrium cesium loading anticipated for the projected waste feed streams. A cesium loading of $133 \mathrm{Ci} /$ liter was selected based on the worst case SRS feed composition [4]. This loading may be overly conservative for Hanford feeds, which typically have higher potassium levels and lower cesium loading. This highly concentrated radioactive source will generate a significant amount of heat in the column, which corresponds to about 0.661 watts/liter of volumetric heat source. Typical loadings are expected to be less than this heat source. Under normal operating conditions, process fluid flow through the column can provide adequate heat removal from the column through a coupled conduction and convection heat transfer mechanism. However, in the case of a loss of flow accident, there are concerns about the transient thermal response rates and the maximum steady-state temperatures reached for fullyloaded columns containing the ion exchange media. Fast thermal response and high peak temperature can lead to unacceptable consequences such as media degradation and solution boiling. For computational modeling purposes, a conservative approach was taken by assuming that the primary cooling mechanisms inside and outside of the column were conduction and natural convection, respectively, and that axial heat removal from the column was negligible relative to radial heat transfer. Figure 1 illustrates the heat transfer mechanisms for the SCIX column system configurations analyzed in this report. The modeling domain was created using a body-fitted coordinate system and structured multi-block grids in the Computational Fluid Dynamics (CFD) preprocessing environment [8].

Non-boiling and non-degradation temperatures will be used as the criteria in the thermal performance analysis. Thus, an operational temperature limit of $65^{\circ} \mathrm{C}$ will be assumed, which is based on data indicating that the resin will have poor performance if it is exposed to this temperature for an extended period, depending on the fluid present [King, 2004]. The safety limit for the supernate filled column will be assumed to be 130 ${ }^{\circ} \mathrm{C}$, since this is the approximate boiling point of waste supernate. Based on the operational limit of $65^{\circ} \mathrm{C}$ and safety limit of $130{ }^{\circ} \mathrm{C}$, three different cases will be studied to select the optimum column design, which satisfies the performance criteria without an internal cooling pipe. For the first case, the maximum column diameters will be determined with no active cooling to maintain the maximum temperature within the bed at or below each of the above limits. The second case will be similar to the first one but with active cooling through the external cooling tubes. The last case will simulate a dry column filled with air as a result of inadvertent loss of the column solution. For the case of the air-filled column, a series of transient modeling calculations will be conducted to determine the maximum bed temperature as a function of time. The modeling results will provide quantitative information associated with the process heat control and management of the SCIX design. Simplified drawings of the column baseline designs for the three cases are shown in Fig. 2.

Thermal modeling will be conducted for a packed bed of RF resin which is saturated in cesium and immersed in waste supernate as well as the case where the same, saturated bed has been inadvertently drained. The baseline maximum cesium loading used will be the same as that used in the previous report which was determined based on anticipated SRS SCIX feeds. This maximum loading is believed to be conservative with regard to Hanford waste since SRS supernates typically have lower potassium (a primary competitor for ion exchange sites) and higher cesium, but this has not been confirmed by calculation. As a result two additional cases will be evaluated using 75 and 
$50 \%$ of the maximum loading. Baseline modeling conditions were used for the present thermal modeling analysis of the SCIX column as shown in Table 1. For Case 1, the maximum column diameters will be determined with no active cooling to maintain the maximum temperature within the bed at or below each of the above limits. Case 2 is similar to Case 1 but with active cooling through the external cooling tubes. Transient calculations will also be conducted for an air-filled column (Case 3) to determine the maximum bed temperature as a function of time. Since a safety temperature limit for dried RF resin has not been determined, this analysis will simply track the maximum temperature profile until a steady state temperature is achieved. Once a safety limit for dried resin is selected, the time required to reach that limit can be determined from these profiles.

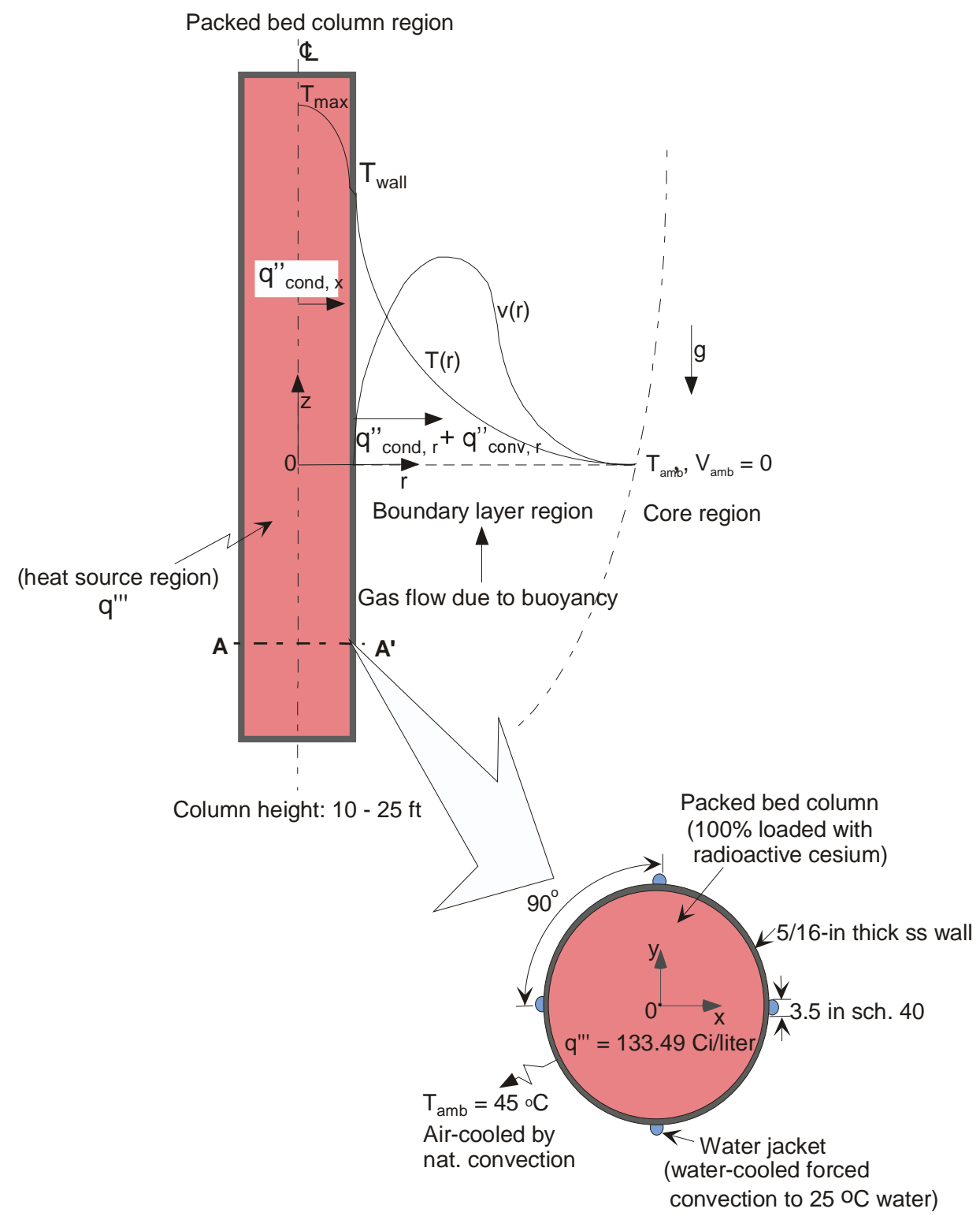

(Cross-sectional 2-D plane along the line A-A')

Figure 1. Typical temperature profiles of packed columns under mixed convection cooling modes and no flow conditions 


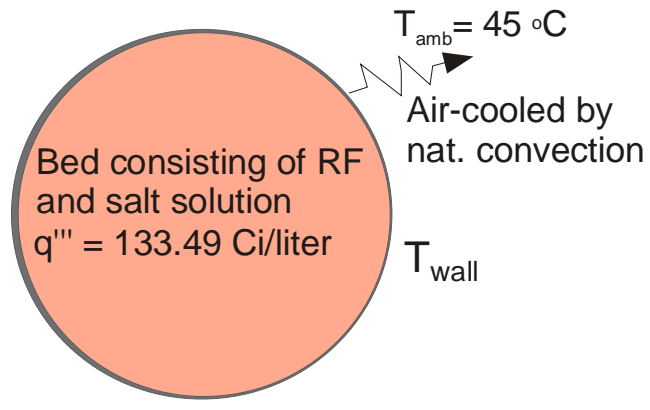

(Case 1)

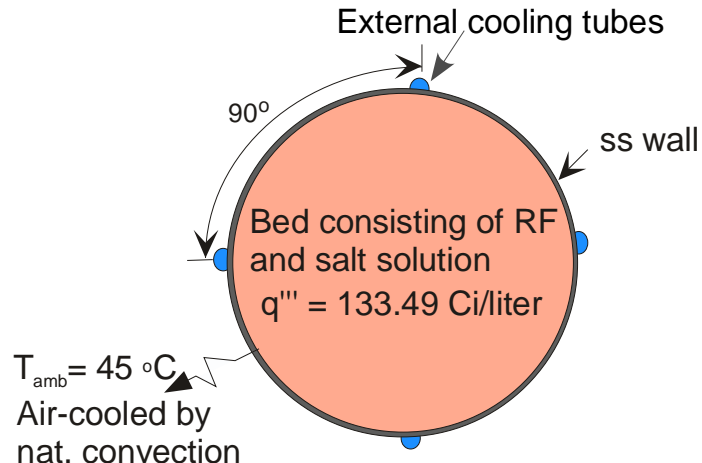

(Case 2)

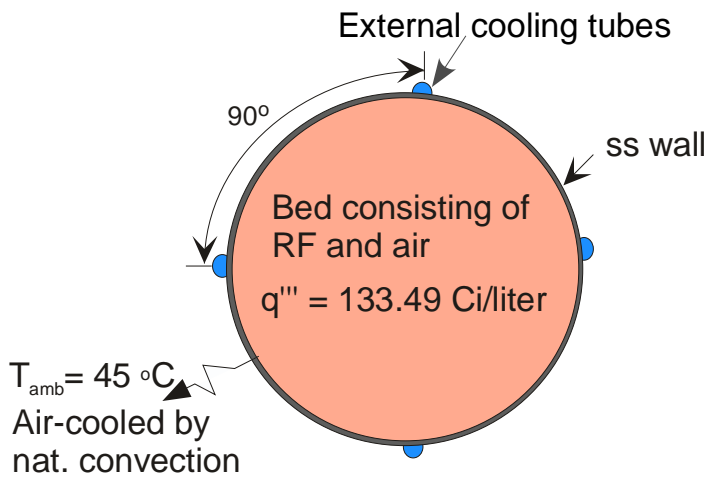

(Case 3)

Heat generated by RF will be cooled by $6.25 \mathrm{gpm}$ flow each coolant tube and natural convection of $45^{\circ} \mathrm{C}$ ambient air.

Figure 2. Three SCIX baseline modeling conditions considered for the analysis.

The three basic cases considered here are as follows:

Case 1: Various column diameters will be studied without active water flow through the external cooling tubes. The column exterior will be cooled only by natural convection with air at $45^{\circ} \mathrm{C}$. The maximum column diameters for which the maximum steady-state temperature within the columns will remain at or below the assumed operational $\left(65^{\circ} \mathrm{C}\right)$ and safety $\left(130^{\circ} \mathrm{C}\right)$ temperature limits will be determined. The primary output from this analysis will be the two column diameters expected to satisfy the two temperature limits with no active cooling system.

Case 2: For Case 2, four external cooling tubes will be considered with coolant flow under a forced convective cooling mechanism. This configuration and design are (Fig. 2) are consistent with the current SRS SCIX column design, but without the internal cooling pipe. The maximum column diameters for which the maximum steady-state temperature within the columns will remain at or below the assumed operational $\left(65^{\circ} \mathrm{C}\right)$ and safety $\left(130^{\circ} \mathrm{C}\right)$ temperature limits will be determined. The primary output from this analysis will be the two column diameters expected to satisfy the two temperature limits 
with active external cooling. One additional case will be evaluated under Case 2 conditions using $50 \%$ of the maximum cesium loading.

Case 3: For the largest diameter determined from the Case 1 and Case 2 analysis (expected to be the Case 2 diameter for the safety temperature limit), transient calculations will be performed for cesium saturated, air filled RF columns to determine maximum bed temperature versus time. In addition, a series of sensitivity calculations will be performed to estimate the transient thermal responses to various diameters and different bed porosities of dry columns under the loss of supernate solution due to an inadvertent drainage event.

All three cases considered here are summarized in Table 2. This analysis will be very conservative in nature and will give bounding temperature data. Only conductive heat transfer within the column bed will be considered and it will be assumed that the thermal conductivity of the resin is constant with temperature. An additional transient calculation will be conducted under Case 3 conditions using 50\% of the maximum cesium loading.

Steady-state calculations will involve the following assumptions (unless otherwise indicated) in order to ensure conservative model results for the maximum centerline temperatures.

- Resin bed is immersed in salt solution with no active or convective liquid flow through the bed (except for Case 3 where the bed is drained).

- RF resin and salt solution are locally in thermal equilibrium so that effective thermal conductivity of the packed bed column can be valid for the analysis.

- For Case 1, there is no forced coolant flow through the cooling tubes, but with the tubes filled with coolant water.

- Column is suspended in unventilated dry air at $45^{\circ} \mathrm{C}$ rather than salt solution within a high level waste tank head space.

- Heat source terms will be the maximum cesium loading of $133 \mathrm{Ci} / \mathrm{L}$ of bed predicted for all of the SRS waste compositions considered for SCIX processing (except for the cases where 75 and $50 \%$ loading is used). Thus, the heat source $\left({ }^{137} \mathrm{Cs}\right.$ and ${ }^{137 \mathrm{~m}} \mathrm{Ba}$ decay) is uniformly distributed throughout the entire packed column and produces 0.661 watts/liter corresponding to the maximum cesium loading.

- Column is filled with a fixed bed of RF particles and salt solution (no convective fluid flow in bed) in a homogeneous packing.

- Outside the column there is no forced convective airflow, so natural convection is the primary heat transfer mechanism from the exterior of the column wall. Radiative cooling contributions at the outer wall surfaces of the column are also considered.

- A typical natural convective heat transfer coefficient $\left(h_{w}\right)$ of $1.5 \mathrm{~W} / \mathrm{m}^{2} \mathrm{~K}$ was used as an external wall boundary condition based on previous analysis [3]. 
Table 1 . Baseline modeling conditions and sensitivity study parameters (parentheses) used for the present heat transfer analysis of the SCIX column.

\begin{tabular}{|c|c|}
\hline Models & Conditions for the baseline model \\
\hline Heat load in RF-loaded SCIX column & $133 \mathrm{Ci} /$ liter (0.661 watts/liter) ${ }^{\#}$ \\
\hline RF porosity & $65.79 \%$ \\
\hline Column hydraulic conditions & no flow \\
\hline Bed conditions & fixed and packed \\
\hline Ambient temperature & $45^{\circ} \mathrm{C}\left(35^{\circ} \mathrm{C}\right)^{*}$ \\
\hline $\begin{array}{l}\text { Heat transfer coefficient at wall, } \\
\qquad h_{w}\left(\mathrm{~W} / \mathrm{m}^{2} \mathrm{sec}\right)\end{array}$ & $\begin{array}{c}1.5 \mathrm{~W} / \mathrm{m}^{2} \mathrm{sec} \\
\text { (typical natural convection)** }^{\star \star}\end{array}$ \\
\hline Diameters of coolant tubes & $\begin{array}{c}3.5 \text { in Sch. } 40 \text { for each of four side } \\
\text { jacket ( } 6 \text { in Sch. } 40 \text { for one central } \\
\text { coolant pipe) })^{\star}\end{array}$ \\
\hline Coolant water flowrate in cooling tubes & $\begin{array}{l}6.25 \mathrm{gpm} \text { for each side jacket }(12.5 \\
\text { gpm for } 6 \text { in central coolant pipe })^{*}\end{array}$ \\
\hline Coolant water temperature & $25^{\circ} \mathrm{C}$ fixed by forced circulation \\
\hline Bed porosity & $43.2 \%(0.360 \text { and } 0.480)^{\star}$ \\
\hline $\begin{array}{l}\text { Exterior wall surface emissivity of the } \\
\text { column }\end{array}$ & 0.3 \\
\hline
\end{tabular}

Note: ${ }^{\#}$ All Curies assumed converted to heat load wattage

Assumed loading is for $25^{\circ} \mathrm{C}$ for conservative evaluations while ambient temperature is $45^{\circ} \mathrm{C}$.

* For sensitivity analysis

** Heat transfer coefficient at the exterior wall of the RF column 
Table 2. Three baseline cases considered for the two-dimensional transient calculations under the column fully loaded with radioactive cesium

\begin{tabular}{|l|c|c|c|c|c|}
\hline Cases & $\begin{array}{c}\text { Modeling } \\
\text { domain } \\
\text { and } \\
\text { boundary } \\
\text { conditions }\end{array}$ & $\begin{array}{c}\text { Modeling simulation } \\
\text { approach }\end{array}$ & $\begin{array}{c}\text { Fluid inside } \\
\text { column }\end{array}$ & $\begin{array}{c}\text { Four } \\
\text { external } \\
\text { cooling } \\
\text { tubes }\end{array}$ & $\begin{array}{c}\text { External cooling } \\
\text { mechanisms }\end{array}$ \\
\hline Case 1 & $\begin{array}{c}\text { Shown } \\
\text { in Fig. 2 }\end{array}$ & Steady state & salt solution & Inactive & Passive cooling \\
\hline Case 2 & $\begin{array}{c}\text { Shown } \\
\text { in Fig. 2 }\end{array}$ & Steady state & salt solution & Active & $\begin{array}{c}\text { Forced convective } \\
\text { cooling with four } \\
\text { cooling tubes }\end{array}$ \\
\hline Case 3 & $\begin{array}{c}\text { Shown } \\
\text { in Fig. 2 }\end{array}$ & $\begin{array}{c}\text { Transient until steady } \\
\text { state solution } \\
\text { reached }\end{array}$ & air & Active & $\begin{array}{c}\text { Forced convective } \\
\text { cooling with four } \\
\text { cooling tubes }\end{array}$ \\
\hline
\end{tabular}

Two-dimensional computational models will be used to determine the temperature distribution across a horizontal slice of the column with end cooling effects neglected (i.e. temperature profiles will be representative of an infinitely long column). Note that this type of analysis applies to even partially loaded RF columns since saturated conditions will typically exist in the top portion of the bed. Case 2 analysis will include the same assumptions except that it will involve forced coolant flow through the outer cooling tubes using $25^{\circ} \mathrm{C}$ coolant water at a flow rate of $6.25 \mathrm{gpm}$. Forced convective heat transfer will occur at the wall/coolant tube boundary in this case with natural convective heat transfer occurring at all remaining external column boundaries with the tank headspace air.

The modeling analysis for the Case 3 conditions involves two-dimensional transient heat transfer calculations for a horizontal plane of the Resorcinol-Formaldehyde (RF) packed bed within an ion exchange column. In this case, a conservative approach was taken to estimate transient temperature profiles of fully-loaded columns filled with air as a result of the accident scenario involving the complete draining of fluid from a fully loaded column. This analysis will be very conservative in nature and will give bounding temperature data. In this situation, the column with heat source was assumed to be cooled by forced convection at the wall regions attached to four cooling tubes and by natural convection cooling at the remaining external wall of the column. Convection cooling effects within the bed were neglected. The effective thermal conductivity of a RF-fluid porous medium was used for the analysis, assuming that the medium is a continuum, and the temperatures of the gas and the solid matrix are equal locally in a stagnant porous media. However, at the elevated temperatures expected for the airfilled columns, particle-to-particle and particle-to-wall heat transfer through the contact points may be significant. Since a safety temperature limit for dried RF resin has not been determined, this analysis will simply track the maximum temperature profile until a steady state temperature is achieved. Once a safety limit for dried resin is selected, the time required to reach that limit can be determined from these profiles.

The transient calculations for Case-3 (air-filled column) will involve the following assumptions: 
- Resin is completely dry throughout the bed and homogeneously packed.

- Air-packed column volume remains fixed, and the air and the RF resin are locally in thermal equilibrium so that effective thermal conductivity of the porous bed can be valid for the analysis.

- Chemical reaction of the resin (including oxidation, ignition, and off-gassing) is negligible.

- Air convection inside the column is conservatively neglected for a fixed bed of dried RF particles in a homogeneous packing. Thus, only conductive heat transfer within the column bed will be considered.

- Radiative cooling contribution at the inner wall surfaces of the column is conservatively assumed to be negligible.

- Column initial temperature is the same as tank ambient temperature of $45^{\circ} \mathrm{C}$.

- For the estimation of the maximum column size under the Case 3 conditions, the cooling tube size is assumed to remain constant (3.5in Schedule 40).

- The water temperature inside the cooling tube is $25^{\circ} \mathrm{C}$.

- The heat source $\left({ }^{137} \mathrm{Cs}\right.$ and ${ }^{137 \mathrm{~m}} \mathrm{Ba}$ decay) is uniformly distributed throughout the entire packed column and produces 0.661 watts/liter assuming that the column is loaded to $133.5 \mathrm{Ci} /$ liter.

- Although air thermal conductivity is considered to be dependent on the column temperature, thermal conductivity of the RF material is constant with temperature.

Based on these assumptions and modeling domains as shown in Fig. 2, the twodimensional governing equations for the present analysis in the Cartesian coordinate system of Fig. 1 are shown below. For a general energy balance equation on a control segment of the column system with volumetric heat source q"',

$\rho_{b, \text { eff }} \frac{\partial i}{\partial t}-\frac{\partial}{\partial x}\left\{k_{b, \text { eff }} \frac{\partial T}{\partial x}\right\}-\frac{\partial}{\partial y}\left\{k_{b, \text { eff }} \frac{\partial T}{\partial y}\right\}-q^{\prime \prime \prime}=0$

where $i$ is enthalpy. The heat source term is included in the present model since a significant amount of decay heat is generated from the ion exchange process through the column packed with RF resin.

In eq. (1), energy terms within a control volume of a solid medium in the column include conduction $(k \nabla T)$ and energy storage due to transients $\left(\rho_{b, \text { eff }} d / \partial=\rho_{b, \text { eff }} C_{p b, \text { eff }} \partial T / \alpha\right)$. In this situation, radiation and convection terms in the energy balance equation were neglected. $K_{b, \text { eff }}$ in eq. (1) is thermal conductivity of the medium in the computational domain. This property value will be provided by the constitutive relation later. The packed column with volumetric heat source q"' will be cooled down by a natural convection process through its wall surface as shown in Fig. 1. In this case, when wall boundary and initial conditions are provided, the governing equations are complete. They are

$-(k \nabla T)_{\text {wall }}=h_{w}\left(T-T_{\infty}\right)_{\text {wall }}$ 
and

$T(t=0)=T_{i}$

In eq. (2), $h_{w}$ and $T_{\infty}$ are wall heat transfer coefficient and ambient temperature, respectively. $T_{i}$ in eq. (3) is initial temperature of the computational domain.

The heat transfer coefficient at the outside wall of the column $\left(h_{w}\right)$ is obtained by using the empirical correlation (eq. (4)) available in the literature. As the baseline modeling conditions of Case-1, the column is assumed to be cooled by the natural convection. In this situation, the natural convection flow regime for the air-cooled design should be estimated based on the non-dimensional Grashof number $\left(\mathrm{Gr}_{\mathrm{L}}\right)$, which is the parameter describing the ratio of buoyancy to viscous forces for a vertically-oriented cylinder with height $L$. The Grashof number performs much the same function for natural convection flow as the Reynolds (Re) number does for forced convection. Under normal conditions one may expect that the laminar-to-turbulent transition will take place between $G r_{L} \approx 10^{9}$ and $10^{10}[8]$.

The modeling analysis for Case 1 and Case 2 conditions involves steady-state heat transfer calculations for a horizontal plane of the Resorcinol-Formaldehyde packed bed within an ion exchange column. The computational modeling domain is shown in Fig. 2. A conservative approach was taken to estimate transient temperature profiles of fullyloaded columns with no process fluid flow. In this situation, the column with heat source was assumed to be cooled only by a typical natural convection mechanism at the column wall and convection within the bed was neglected.

A typical natural convective heat transfer coefficient $\left(h_{w}\right)$ of $1.5 \mathrm{~W} / \mathrm{m}^{2} \mathrm{~K}$ was used as an external wall boundary condition from the previous works $[4,8,10,17]$. The present value of the heat transfer coefficient can be justified on the following basis:

For a conservative calculation, a low temperature gradient at the wall boundary layer was used to estimate natural convection capability for the present geometrical configurations. Heat transfer coefficient $\left(h_{w}\right)$ for natural convective cooling under a turbulent flow regime $\left(\mathrm{Ra}_{f}=\mathrm{Gr}_{L} P r_{f}>10^{9}\right)$ is given in terms of non-dimensional numbers empirically.

$$
N u_{L}=\frac{h_{w} L}{k_{w}}=C\left(G r_{L} \operatorname{Pr}_{f}\right)^{m} \quad \text { for } \operatorname{Gr}_{L} \operatorname{Pr}_{f}<10^{12}
$$

where $\mathrm{C}$ and $\mathrm{m}$ are the coefficients determined from literature data and $L$ is the characteristic length of the RF column.

For the present geometrical configuration, $\mathrm{C}=0.10$ and $\mathrm{m}=0.333$ are given by Warner and Arpaci using the experimental data [8]. From eq. (4), the heat transfer coefficient $\left(h_{w}\right)$ is about $1.5 \mathrm{~W} / \mathrm{m}^{2} \mathrm{~K}$ corresponding to $N u_{L} \approx 254$ conservatively under the present conditions. Figure 3 shows the quantified results for the literature correlation based on laminar natural convection, which was developed by Warner and Arpaci. The figure shows the conservatism imbedded in the present modeling conditions for the natural convection through the exterior wall surface of the RF column containing the decay heat source. 
Heat transfer coefficients $\left(h_{w f}\right)$ for forced convective heat transfer mechanisms through the column wall attached to the water jackets and through the inner surface of the coolant pipe at the column center were estimated by Dittus-Boelter's correlation [21]. That is,

$$
N u_{d}=\frac{h_{w f} d_{h}}{k_{w f}}=0.023\left(R e_{d}\right)^{0.8}\left(P r_{w f}\right)^{a} \text { for } R e_{d}>2000
$$

Equation (5) is applicable to turbulent flow when the Reynolds number is larger than 2,000 in terms of the hydraulic diameter $d_{h}$, and the parameter $a$ in eq. (5) is 0.4 when the fluid is heated as modeled in the present work. The Reynolds number for the present study is about 7,000 when $6.25 \mathrm{gpm}$ flowrate of water flows through the 3.5-in half-moon coolant tubes, which corresponds to $0.25 \mathrm{~m} / \mathrm{sec}$ flow velocity. In the present work, one of two bounding cases, Case 2, includes a forced convection mechanism as shown in Table 3. Forced convection heat transfer coefficients at the water jackets $\left(h_{w f}\right)$ attached to the exterior of the column wall and at the inner surface of 6-in water pipe were estimated by eq. (5). From the baseline modeling condition, the wall heat transfer coefficient governed by a forced convection mechanism was estimated as $h_{w f}=213$ $\left(\mathrm{W} / \mathrm{m}^{2} \mathrm{~K}\right)$ for the wall surface of the 6 -in central coolant pipe and $h_{w f}=620\left(\mathrm{~W} / \mathrm{m}^{2} \mathrm{~K}\right)$ for the wall of 3.5-in water jacket. Figure 4 shows quantified results for the present modeling conditions in terms of Reynolds number.

The main design parameters involved for the heat transfer in a fixed bed SCIX column are as follows:

- Ambient air temperature around the column system

- Heat load of the RF resin column

- Bed thermal characteristics

- External and internal heat removal capability of the column such as coolant pipe size and flow conditions

Table 2 presents the modeling boundary conditions for the base cases of the present column loaded with RF resin. Table 3 shows a range of total heat loads generated by the cesium absorption from salt solution into the RF resin materials during normal operation of the SCIX column. These heat loads will be used as heat source term q"' in eq. (1) for the modeling calculations. 


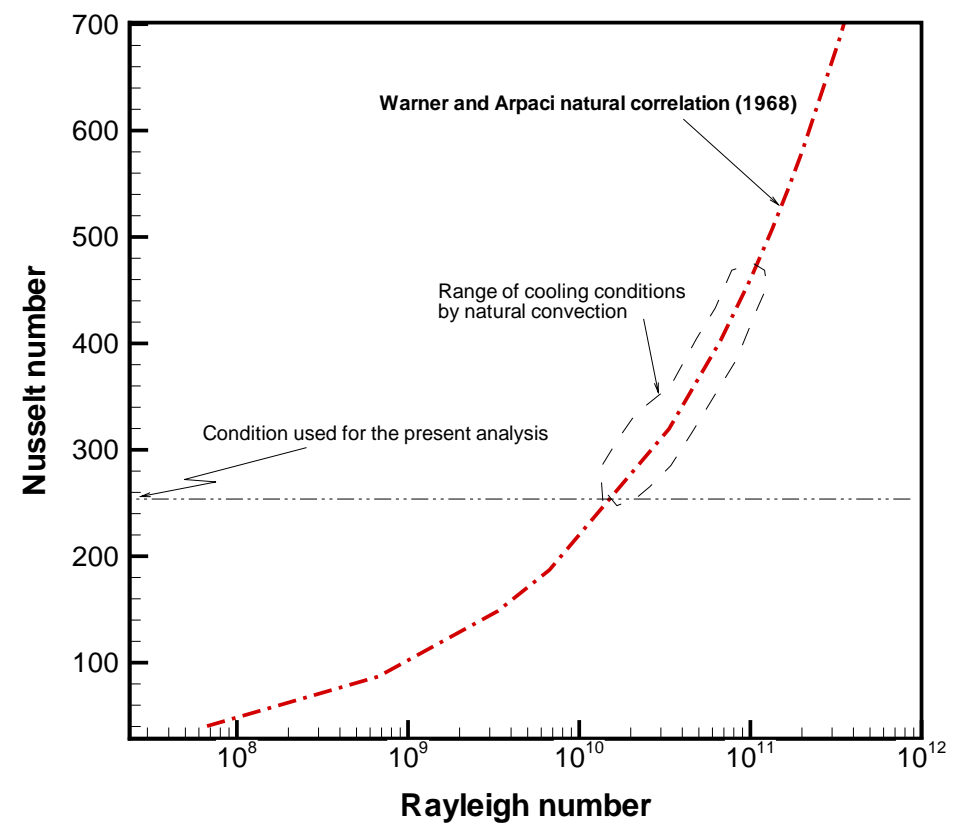

Figure 3. Natural convection heat transfer correlation available in the literature showing the conservatism imbedded in the present heat transfer analysis.

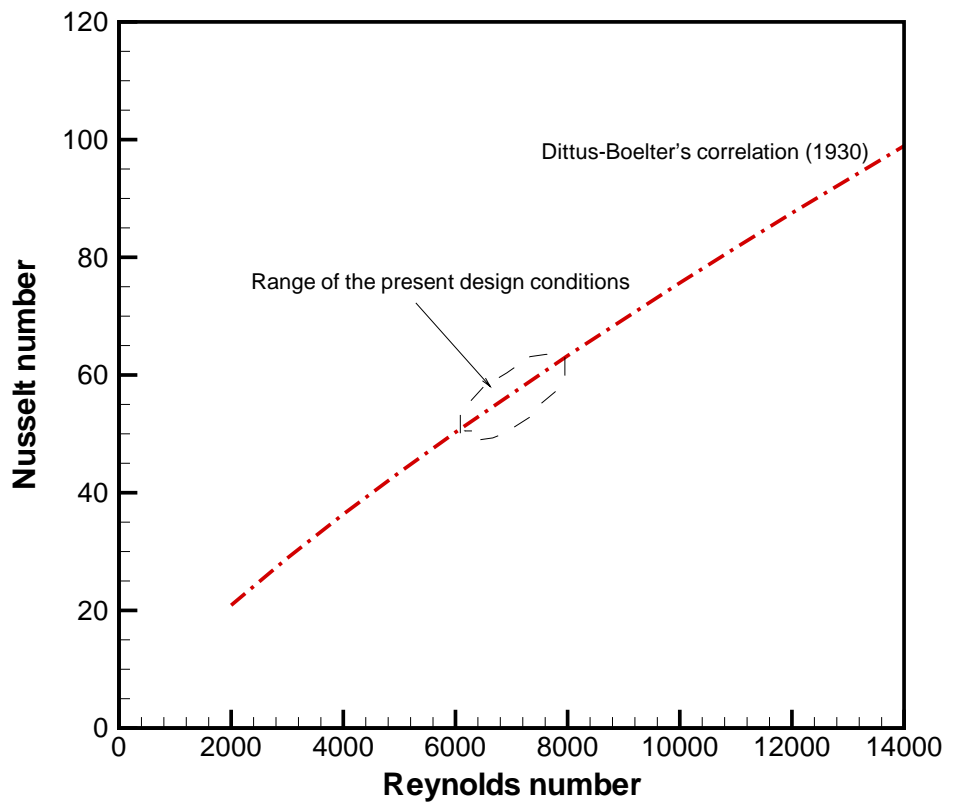

Figure 4. Forced convection correlation available in the literature demonstrating the range of the convective heat transfer through the water cooling system of the SCIX column. 
Table 3. Heat source terms for the 28 -in baseline RF column used for the present study

\begin{tabular}{|c|c|c|c|}
\hline $\begin{array}{c}\text { Column } \\
\text { height } \\
\text { (ft) }\end{array}$ & $\begin{array}{c}\text { Column heat load, } \\
\text { q'” } \\
\text { Ci/liter [watts/liter] }\end{array}$ & $\begin{array}{c}\text { Total column } \\
\text { volume } \\
\text { (liters) }\end{array}$ & $\begin{array}{c}\text { Total heat sources } \\
\text { generated by column } \\
\text { loading (watts)* }\end{array}$ \\
\hline 10 & $133.49[0.661]$ & 1210.2 & 799.7 \\
\hline 15 & $133.49[0.661]$ & 1815.3 & 1199.5 \\
\hline 25 & $133.49[0.661]$ & 3025.6 & 1999.2 \\
\hline
\end{tabular}

Note:*Conversion factor for Cs-137 decay heat is 0.00495 watts/Ci.

The solution methodology has been established to calculate transient temperature response of the column system to the column heat load q"' as provided in Table 3. The transient calculations were continued until maximum temperatures for the components were reached. In this work, two temperature limits are used for the operation and safety criteria in the design evaluation of the RF column. One is an operating temperature limit to prevent degradation of RF resin, which is the $65^{\circ} \mathrm{C}$ temperature limit of the bed column containing the heat source. The other is used as a safety limit, which is the $130^{\circ} \mathrm{C}$ temperature limit of the salt solution boiling.

Complete setup of the modeling calculations requires the input parameters such as thermal and material properties of the components, heat source term, and initial / boundary conditions along with the established modeling domain. The material and thermal properties for the column components are provided in Table 4.

For the heat transfer analysis of the RF column, the governing equations are applied to the two-dimensional computation domain as shown in Fig. 1, assuming that the axial heat transfer of the column is negligible. There is heat source information (q"' in eq. (1)) for the column region. For conservative heat transfer calculations, the heat source was estimated for a fully-loaded and uniformly-distributed bed packed with RF solid material. The current calculations used $133 \mathrm{Ci} /$ liter for RF resin, corresponding to 0.661 watts/liter, as volumetric heat source q"' as shown in Table 3. Total powers generated by the RF column were obtained by multiplying the volumetric source by total column volume for each of the three different column heights $(10,15,25 \mathrm{ft})$. This information was based on the previous modeling results [4]. In addition, this region was included as a conduction zone and was assumed to have constant thermal conductivity instead of considering temperature-dependency for the steady-state energy equation. However, the transient model considered temperature-dependent thermal properties to predict transient thermal responses of the fixed bed region in case of the loss of the salt process flow. For computational efficiency, effective thermal conductivity of the bed column was used from the experimental correlation available in the literature [2].

The material and thermal properties for the components of the RF packed column system are provided in Table 4. Using these thermal properties, two-dimensional steady-state and transient conduction models were performed to estimate maximum column temperature of the RF fixed bed and to find transient thermal response of the bed region in case of the loss of the RF process fluid. For computational efficiency, effective thermal conductivity for the composite column region was used. Effective 
thermal conductivity of the RF bed region was estimated by the literature correlation [7]. That is, effective thermal conductivity of the bed $\left(k_{b, \text { eff }}\right)$ was developed as function of the bed porosity $\varepsilon$ in $\mathrm{SI}$ unit $(\mathrm{W} / \mathrm{mK})$ using the literature experimental data.

$k_{b, \text { eff }}=k_{f}\left(\frac{k_{\text {peff }}}{k_{f}}\right)^{A+B \log \left(\frac{k_{\text {peff }}}{k_{f}}\right)}$

where

$$
\begin{aligned}
& A=0.280-0.757 \log \varepsilon \text { and } B=-0.057 . \\
& k_{\text {peff }}=\varepsilon_{p} k_{f}+\left(1-\varepsilon_{p}\right) k_{p}
\end{aligned}
$$

In eq. (6), $k_{\text {peff }}$ is effective thermal conductivity of RF particle considering particle porosity $\varepsilon_{p} . k_{f}$ in eq. (8) is thermal conductivities of the stagnant fluid trapped inside the porous RF particle. Coefficient $A$ is a function of the bed porosity $\varepsilon$. The thermal conductivity of the RF particle $\left(k_{p}\right)$ is assumed to be constant for conservative estimation and computational efficiency.

Thermal properties of phenolic plastic material [14], which is similar to RF resin, were used for the evaluation of effective thermal conductivity for the RF-salt column since no known measurements of the thermal properties of spherical RF resin have been reported. Phenolic plastic polymer is expected to have similar thermal properties to resorcinol formaldehyde polymer due to similarities in chemical structure for these materials.

Effective material properties of the RF column are computed in terms of the bed porosity of the packed column $\varepsilon$. Effective density $\rho_{b, \text { eff }}$ and specific heat $C p_{b, \text { eff }}$ of the bed column are based on a homogeneous assumption. That is,

$\rho_{b, \mathrm{eff}}=\varepsilon \rho_{f}+(1-\varepsilon) \rho_{\text {peff }}$

Effective particle density $\rho_{\text {peff }}$ is given by particle porosity $\varepsilon_{p}$.

$$
\begin{aligned}
& \rho_{\text {peff }}=\varepsilon_{p} \rho_{f}+\left(1-\varepsilon_{p}\right) \rho_{p} \\
& C p_{b, \text { eff }}=\varepsilon C p_{f}+(1-\varepsilon) C p_{\text {peff }}
\end{aligned}
$$

Effective particle specific heat $C p_{\text {peff }}$ is given by particle porosity $\varepsilon_{p}$.

$$
C p_{\text {peff }}=\varepsilon_{p} C p_{f}+\left(1-\varepsilon_{p}\right) C p_{p}
$$

In eqs. (9) and (10), subscripts $f$ and $p$ refer to the fluid and particle materials within the packed bed, respectively. Thus, computational time can be reduced by modeling a single-material region with the effective thermal conductivity instead of modeling a multimaterial region composed of two different materials. This leads to a reduction in the computational time and effort with reasonable accuracy.

The two-dimensional geometry was created using the multi-block preprocessor of the Fluent ${ }^{\mathrm{TM}}$ code [8] under the body-fitted coordinate system, which allows the treatment of non-orthogonal geometries. The present model consists of 2 element blocks and 2 different material zones on the $x$-y computational plane. Non-uniform two-dimensional structured meshes of the computational domain were used to capture the smooth temperature gradient across the boundary zone of the two different material regions. 
Typical modeling boundaries for the cases considered here are shown in Fig. 2. The governing equations discretized by computational grid were solved by an iterative solution method.

The overall energy balance should be checked to demonstrate the adequacy of the grid fineness used. This was done by using eq. (13).

$R=-\int_{A_{W}} q_{W}^{\prime \prime} d A+q^{\prime \prime \prime} V_{b}$

The volumetric heat source term, q'", in eq. (13) is given by the code input. For all the cases considered here, absolute value of energy residual $(R)$ is kept to be less than about 0.5 watt. For instance, the residual results for the Case 1 model of the RF-salt solution bed are shown as function of grid number in Fig. 5. For the present analysis, an optimum grid of about 8,100 cells for the 28 -in column has been established from the grid sensitivity analysis under the Linux high performance platform. Nonuniform twodimensional meshes used for the computational analysis of the 28-in column are shown in Fig. 6.

Table 4. Material and thermal properties for heat transfer calculations of the RF column

\begin{tabular}{|c|c|c|c|c|}
\hline \multicolumn{2}{|c|}{ Material } & $\begin{array}{c}\text { Thermal conductivity } \\
(\mathrm{W} / \mathrm{mK})\end{array}$ & $\begin{array}{c}\text { Density } \\
(\mathrm{kg} / \mathrm{m} 3)\end{array}$ & $\begin{array}{c}\text { Specific heat } \\
(\mathrm{J} / \mathrm{kgK})\end{array}$ \\
\hline Ion exchange resin & $\mathrm{RF}^{\star}$ & 0.2770 & $1615.0^{\star *}$ & 1109.5 \\
\hline Salt solution & 0.68 & 1232.0 & 3630.0 \\
\hline RF-salt solution & $0.5987^{\#}$ & $1306.4^{\#}$ & 3140.2 \\
\hline Air & Temp.-dependent & Ideal gas & 1010.0 \\
\hline RF-air medium & $0.0566^{\#}$ & $314.7^{\#}$ & 1029.3 \\
\hline Stainless steel & 17.30 & 7800.0 & 486.0 \\
\hline
\end{tabular}

Note: \# based on non-linear empirical correlation of Krupiczka [7] at $25{ }^{\circ} \mathrm{C}$ considering particle porosities ( $\varepsilon_{p}=65.79 \%$ for RF particle) and the volume fractions of air or fluid in the packed beds ( $\varepsilon=0.432$ for RF bed), giving total bed porosity of 0.80 for RF, respectively (total porosity evaluated considering bead and bed porosities.)

\#\# $k_{\text {air }}=3.3350 \times 10^{-3}+8.0021 \times 10^{-5}\left(273.15+t_{\text {air }}\right)-1.8975 \times 10^{-8}\left(273.15+t_{\text {air }}\right)^{2}$, where $t_{\text {air }}$ is in ${ }^{\circ} \mathrm{C}$ [9].

* based on Phenolic plastic material similar to RF [16]

** based on material density (not bulk density) 


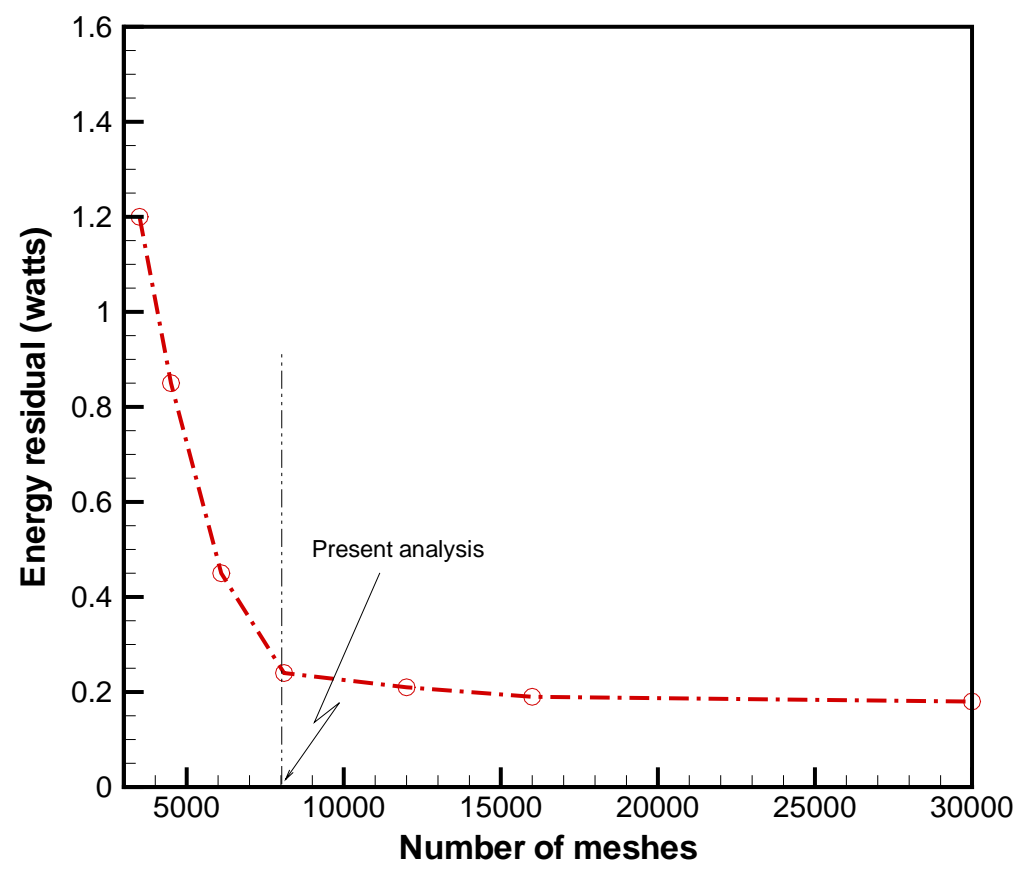

Figure 5. Sensitivity results associated with numerical energy residual showing that about 8,100 meshes are established for the present analysis

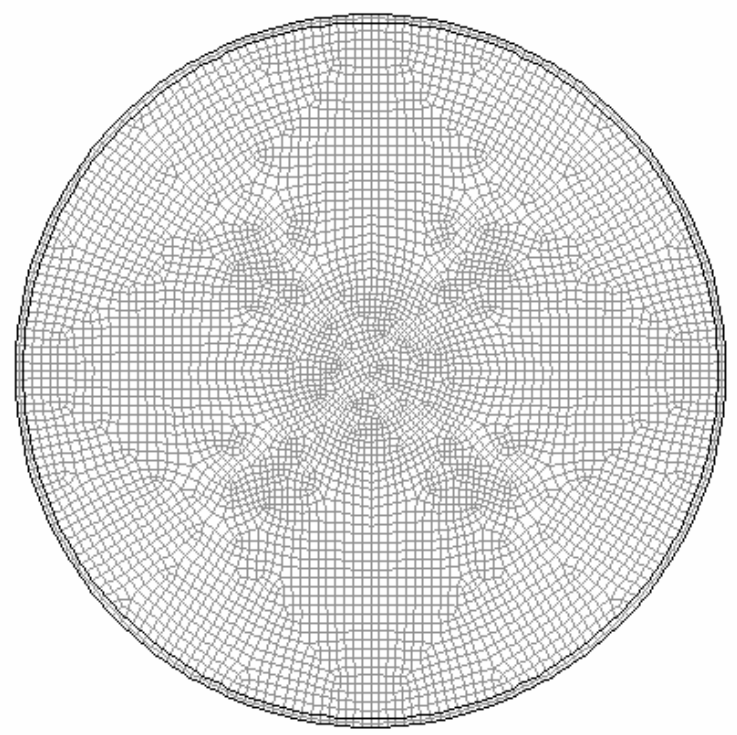

Figure 6. Computational nodes for the two-dimensional computational domain of the 28-in column (8,100 nodes) 


\subsection{MODELING RESULTS AND DISCUSSION}

Thermal performance calculations were performed for the RF baseline column fully loaded with cesium using the modeling boundary conditions as shown in Fig. 2 and the established number of meshes as shown in Fig. 6. Material and thermal properties used for the calculations are shown in Table 4. In all cases, the convection effect for the column bed was assumed to be negligible for the conservative estimate of maximum column temperature. The column for Case 1 is cooled only by natural convection, and the wet and drained columns for Case 2 and Case 3 are cooled by forced convective cooling of four external cooling tubes and natural convection of the remaining column wall. Ambient temperature of $45^{\circ} \mathrm{C}$ for all cases was assumed to remain constant.

The performance model was benchmarked against the theoretical results to verify the computational results. The results are discussed in the subsequent sections.

\subsection{BENCHMARKING RESULTS}

A theoretical approach for steady-state conduction heat transfer of a two-layered cylinder containing a heat generation source was taken to verify the present computational model under the geometrical and physical conditions shown in Fig. 7 for a RF-packed column without a central cooling tube. All mathematical notations used in the benchmarking are included in the figure. These evaluations were conducted to benchmark and validate the heat transfer model. The theoretical model was based on a steady state conduction approach for the domain including heat source. The steady state energy conservation equation for the RF packed column with effective thermal conductivity $k_{b, \text { eff }}$ becomes

$$
k_{b, \text { eff }} \nabla^{2} T+q^{\prime \prime \prime}=0
$$

For the RF column region with a uniformly distributed heat generation source q"' as shown in Fig. 7, eq. (14) becomes

$$
\frac{d^{2} T}{d r^{2}}+\frac{1}{r} \frac{d T}{d r}+\frac{q^{\prime \prime \prime}}{k_{b, \text { eff }}}=0
$$

As boundary conditions, the following relations at the center and wall of the RF column are applied to the above equation, eq. (15).

$$
\begin{aligned}
& \left.\frac{d T}{d r}\right|_{r=0}=0 \\
& T(r=R)=T_{S}
\end{aligned}
$$

After integrating eq. (15) and applying the boundary conditions, the radial temperature distribution for the RF column region with heat generation source q"' becomes 
$T(r)=T_{\text {bed }}(r)=T_{s}+\frac{q^{\prime \prime \prime}}{4 k_{b, \text { eff }}}\left(R^{2}-r^{2}\right) \quad(0 \leq r \leq R)$

Temperature distributions for the stainless wall region $(R \leq r \leq(R+d))$ with no heat source $\left(q^{\prime \prime}=0\right)$ is governed by

$\frac{d^{2} T}{d r^{2}}+\frac{1}{r} \frac{d T}{d r}=0$

Boundary conditions at the wall of the column are

$T(r=(R+d))=T_{w}$

and

$q_{w}^{\prime \prime}=-\left.k_{w} \frac{d T}{d r}\right|_{r=(R+d)}=h_{w}\left(T_{w}-T_{a m b}\right)$.

where $d$ is the stainless steel wall thickness of the RF column, and $k_{w}$ is thermal conductivity of stainless steel wall.

In eq. (21) the wall heat flux $\left(q_{w}^{\prime \prime}\right)$ can be obtained by the energy balance between the heat source and the heat sink when the volumetric heat source q"' is spatially uniform in Region-A of Fig. 7. The resulting equation for the wall heat flux is

$$
q_{w}^{\prime \prime}=q^{\prime \prime \prime}\left(\frac{V_{b}}{A_{w}}\right)=q^{\prime \prime \prime}\left\{\frac{\pi R^{2} L}{2 \pi(R+d) L}\right\}=q^{\prime \prime \prime}\left\{\frac{R^{2}}{2(R+d)}\right\}
$$

Using eqs. (20), (21), and (22), the radial temperature distribution of the RF wall region, Region- $\mathrm{B}$, with no heat source $\left(q^{\prime \prime}=0\right)$ becomes

$$
\begin{aligned}
T(r) & =T_{w}+\frac{q_{w}^{\prime \prime}(R+d)}{k_{w}} \ln \left(\frac{R+d}{r}\right) \\
& =T_{w}+\frac{q^{\prime \prime \prime} R^{2}}{2 k_{w}} \ln \left(\frac{R+d}{r}\right) \quad(R \leq r \leq(R+d))
\end{aligned}
$$

The surface temperature can be evaluated by eq. (23). That is,

$T_{s}=T_{w}+\frac{q^{\prime \prime \prime} R^{2}}{2 k_{w}} \ln \left(\frac{R+d}{R}\right)$ 


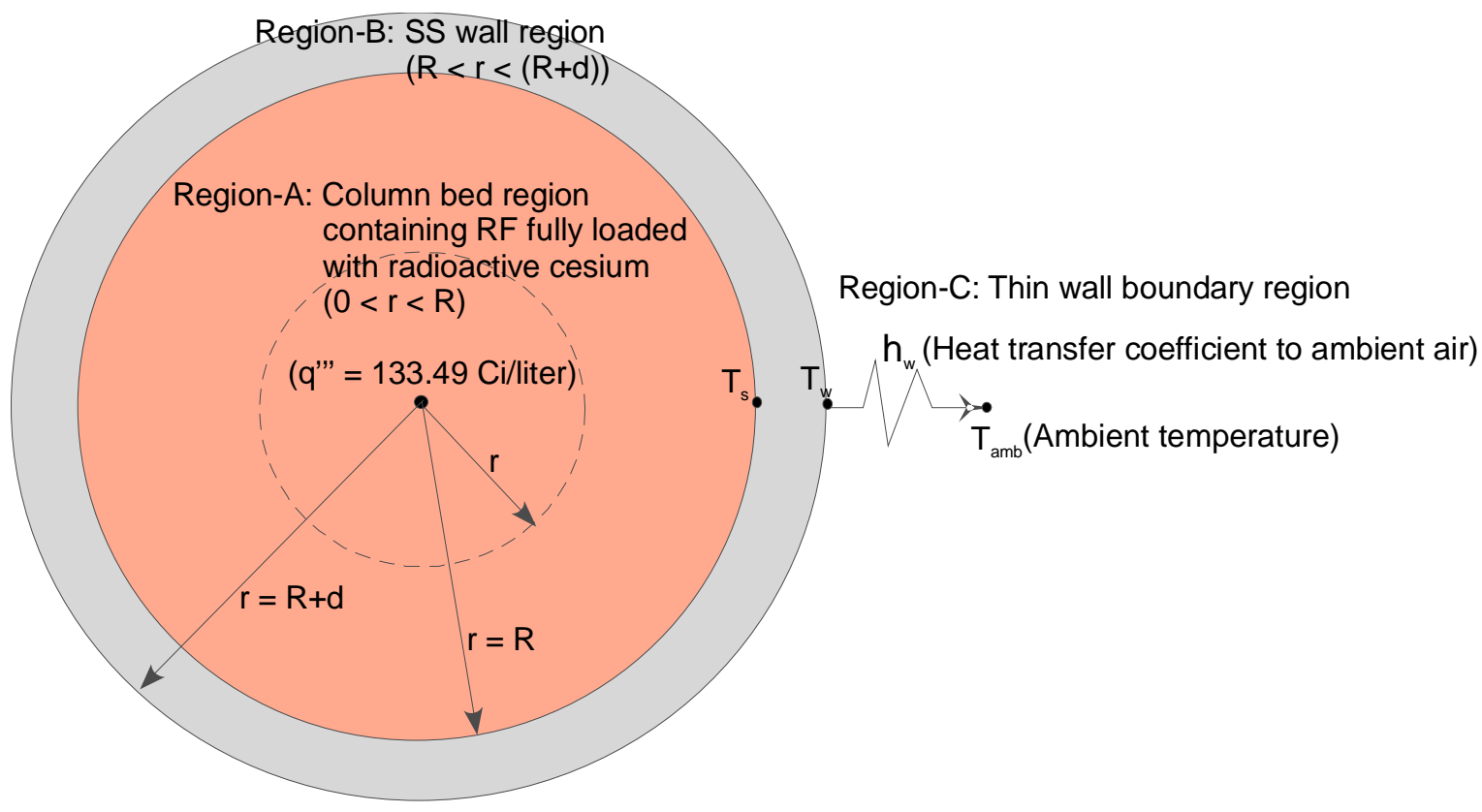

Figure 7. Graphical illustration of the heat transfer model of the RF column under natural convection cooling for the benchmarking analysis.

Table 5. Three regions used for the benchmarking analysis against the computational model

\begin{tabular}{|c|c|c|c|c|}
\hline \multicolumn{2}{|c|}{ System regions } & \multirow{2}{*}{$\begin{array}{c}\text { Volumetric Heat } \\
\text { source, q'” }\end{array}$} & \multicolumn{2}{c|}{$\begin{array}{c}\text { 2-D thermal resistance } \\
\text { ( }{ }^{\circ} \text { C/watts) }\end{array}$} \\
\cline { 4 - 5 } Material region & Domain range & Values* & Theoretical eq. \\
\hline $\begin{array}{c}\text { RF-salt region } \\
\text { (Region-A) }\end{array}$ & $(0 \leq r \leq R)$ & $\begin{array}{c}133.49 \text { Ci/liter } \\
(0.661 \text { watts/liter) }\end{array}$ & $1.3292 \times 10^{-1}$ & $\left(\frac{1}{4 \pi k_{b, \text { eff }}}\right)$ \\
\hline $\begin{array}{c}\text { SS column wall } \\
\text { (Region-B) }\end{array}$ & $(R \leq r \leq(R+d))$ & 0 & $2.0768 \times 10^{-4}$ & $\ln \left(\frac{R+d}{R}\right) / 2 \pi k_{w}$ \\
\hline $\begin{array}{c}\text { Nat. convective } \\
\text { wall boundary } \\
\text { (Region-C) }\end{array}$ & $((R+d) \leq r)$ & 0 & $7.5788 \times 10^{-3}$ & $\left(\frac{1}{2 \pi h_{w}(R+d)}\right)$ \\
\hline
\end{tabular}

Note:* Thermal resistance values for the 28 -in salt-RF column 
The wall surface temperature of the RF column $\left(T_{w}\right)$ can be obtained by eqs. (21) and (22) at $r=(R+d)$ in terms of the convection heat transfer coefficient $\left(h_{w}\right)$ at the column wall surface and the ambient temperature $\left(T_{a m b}\right)$ of Region-C shown in Fig. 7.

$$
\begin{aligned}
T_{w} & =T_{\text {amb }}+\frac{q^{\prime \prime}{ }_{w}}{h_{w}} \\
& =T_{a m b}+\frac{q^{\prime \prime \prime}}{2 h_{w}}\left(\frac{R^{2}}{R+d}\right)
\end{aligned}
$$

From eqs. (18), (24), and (25), the center temperature of the RF-fluid bed region can be obtained in terms of the natural convection boundary condition and the ambient temperature.

$$
T(r=0)=T_{\text {amb }}+\left(\frac{q^{\prime \prime \prime} R^{2}}{2}\right)\left\{\frac{1}{h_{w}(R+d)}+\frac{1}{k_{w}} \ln \left(\frac{R+d}{R}\right)\right\}+\frac{q^{\prime \prime \prime}}{4 k_{b, \text { eff }}} R^{2}
$$

The temperature distribution for each region can be non-dimensionalized in terms of the column wall temperature difference $\left(T_{w}-T_{\text {amb }}\right)$ and the column radius $(\mathrm{R}+\mathrm{d})$ to examine the impacts of the design parameters on the RF temperature distributions. Nondimensional parameters as shown in Fig. 8 are defined as follows:

$$
\eta=\frac{r}{(R+d)} \text { and } \theta_{w}(r)=\left(\frac{T(r)-T_{a m b}}{T_{w}-T_{a m b}}\right)
$$

Temperature and length scales are non-dimensionalized in terms of the column temperature difference $\left(T(r=(R+d))-T_{\text {amb }}\right)$ and the column radius $(R+d)$ as shown in eq. (27).

For region-A $(0 \leq \eta \leq(R /(R+d)))$, the non-dimensional temperature distribution can be obtained from eqs. (18), (24), (25), and (27).

$$
\theta_{w}(\eta)=1+\frac{B i}{2} \ln \left(\frac{R+d}{R}\right)+\frac{B i}{4}\left(\frac{k_{w}}{k_{b, \text { eff }}}\right)\left\{1-\left(\frac{R+d}{R}\right)^{2} \eta^{2}\right\}
$$

The Biot number (Bi) in eq. (28) is defined as the ratio of convection at the wall surface to the conduction through the column wall region. That is

$$
B i=\frac{h_{w} D}{k_{w}}=\frac{2(R+d) h_{w}}{k_{w}}
$$

Thus, the Biot number compares the relative magnitudes of surface convection and internal conduction resistance to heat transfer. A very low value for the Biot number means that internal conduction resistance is negligible in comparison with surface convection resistance. This in turn implies that the temperature will be nearly uniform throughout the conduction media. 
The non-dimensional temperature distribution for the region-B $(R /(R+d) \leq \eta \leq 1)$ can be obtained from eqs. (23) and (27).

$$
\theta_{w}(\eta)=1-\frac{B i}{2} \ln \eta
$$

From eq. (28) the maximum temperature of the RF column with a thin wall thickness under steady-state condition becomes

$$
\theta_{w, \max }=1+\frac{B i}{2} \ln \left(\frac{R+d}{R}\right)+\frac{B i}{4}\left(\frac{k_{w}}{k_{b, \text { eff }}}\right) \approx 1+\frac{B i}{4}\left(\frac{k_{w}}{k_{b, \text { eff }}}\right)
$$

Thus, the non-dimensional temperature distributions inside the RF column and wall regions can be computed in terms of column wall Biot number for a given thermal conductivity ratio of the wall to bed regions, and they can be compared with the steadystate numerical results to verify the model predictions. Larger values of the Biot number imply that the heat conduction inside the body is much slower than the heat convection away from its surface, and temperature gradients becomes larger inside of the body.

In this case, the numerical solution was obtained by solving the transient governing equations with a sequence of time steps until a steady-state solution is reached. Eq. (31) shows that the maximum temperature gradient is closely related to the Biot number and the ratio of thermal conductivity for the column wall region to the effective thermal conductivity of the composite RF column. For a given geometry and wall cooling conditions, the effective thermal conductivity is found to be the key parameter to control the maximum temperature difference between the column center and its wall.

The results show that when the material and thermal properties of the column system remain constant and the volumetric heat load is $133 \mathrm{Ci} /$ liter for the purpose of benchmarking, the steady-state temperature differences for the RF-salt solution columns between the column center and wall are about $15{ }^{\circ} \mathrm{C}$ for the 18 -in column, about $33^{\circ} \mathrm{C}$ for the 28-in column, respectively. Table 6 shows quantitative comparison of the modeling results with the theoretical values for two different RF column diameters. Figure 8 shows comparisons of the theoretical values with the present modeling prediction results for the verification of the present calculations. It is shown that the present computational results are in good agreement with the theoretical results to within about $0.01 \%$.

Table 6. Quantitative comparison between theoretical and modeling results for two different

\begin{tabular}{|c|c|c|c|c|}
\hline \multirow{2}{*}{$\begin{array}{l}\text { Column diameter } \\
\text { (inches) }\end{array}$} & \multirow{2}{*}{$\begin{array}{l}\text { Biot number } \\
\text { (Bi) }\end{array}$} & \multirow{2}{*}{$\left(k_{w} / k_{b, e f f}\right)$} & \multicolumn{2}{|c|}{$\theta_{\mathrm{w}, \max } /\left(\mathrm{T}_{\max }-\mathrm{T}_{\mathrm{amb}}\right)$} \\
\hline & & & Theory & Model \\
\hline 14 & 0.041 & 28.9 & $1.2973 / 63.85$ & 1.2964 / 63.86 \\
\hline 28 & 0.062 & 28.9 & 1.4462 / 108.27 & $1.4456 / 108.30$ \\
\hline
\end{tabular}
RF column sizes 

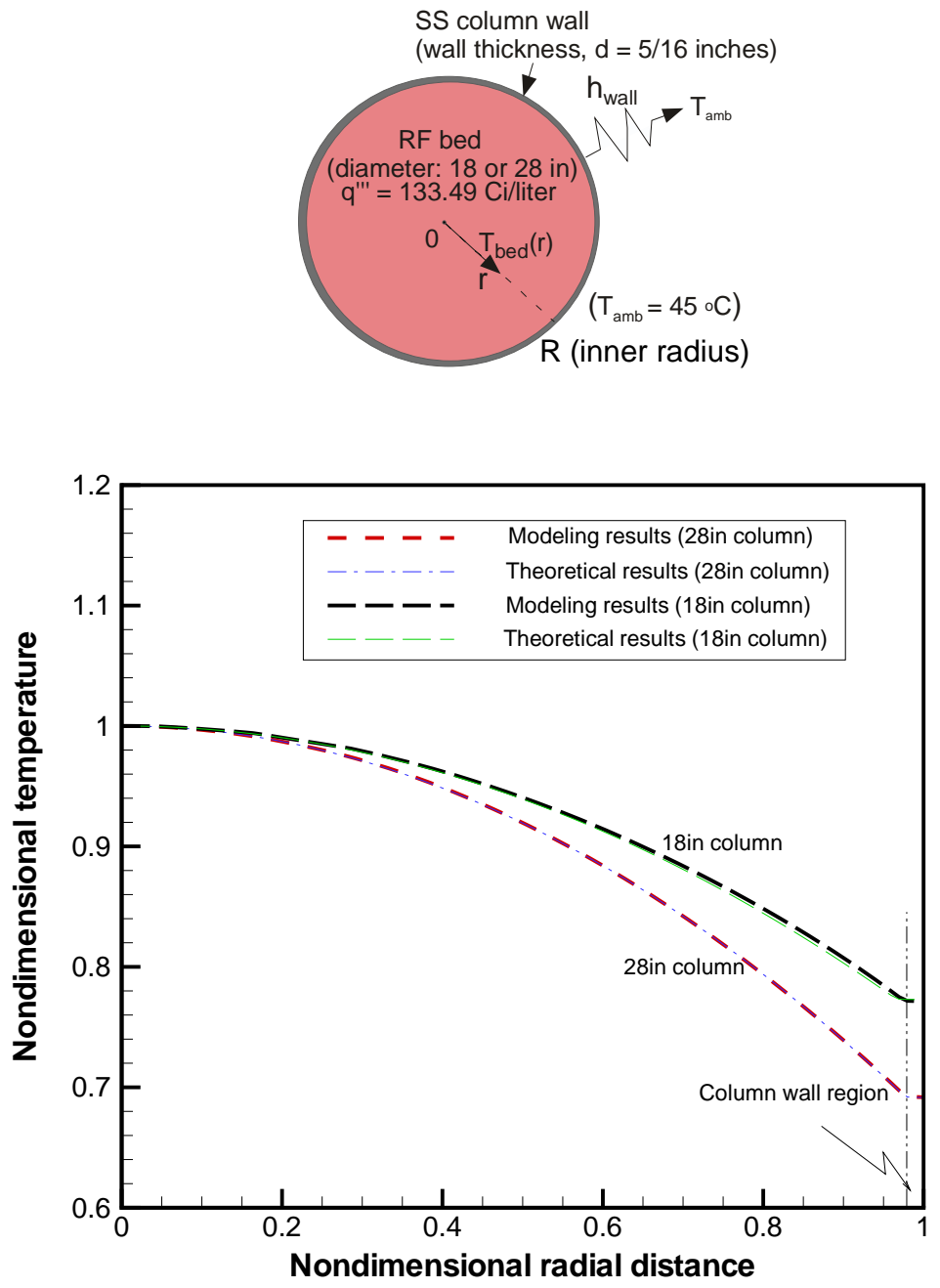

$$
\begin{gathered}
\text { (Nondimensional radial distance } \eta=\frac{r}{R+d}, \\
\text { Nondimensional temperature } \left.\theta_{m}=\frac{T(t \rightarrow \infty, r)-T_{a m b}}{T(t \rightarrow \infty, r=0)-T_{a m b}}\right)
\end{gathered}
$$

Figure 8. Comparison of steady state results between the numerical predictions and theoretical results for the cylindrical column with $133.49 \mathrm{Ci} /$ liter heat load for the model benchmarking. 


\subsection{RESULTS FOR CASE 1}

For Case 1 analysis, 100\% cesium loading (based on the maximum cesium loading anticipated for SRS SCIX waste [4]), no active cooling, no central cooling tube, and 45 ${ }^{\circ} \mathrm{C}$ ambient temperature were considered to be the baseline conditions. Other baseline conditions and parameters are provided in Table 1 and the modeling conditions for each analysis case are shown graphically in Figure 2. Sensitivity studies were also conducted using two additional cesium loadings of 75 and $50 \%$ of the maximum and one additional ambient temperature. The calculated temperature distribution for a 32-in RF column with $100 \%$ cesium loading is shown in Fig. 9. Maximum column temperatures for various column diameters are presented for the three different cesium loadings considered in Fig. 10. Table 7 compares the results in a quantitative way. The maximum column diameter satisfying the assumed media (or operational) temperature limit under these conditions increases by 67\% (from 12 inch to 20 inch diameter) when the cesium loading is decreased by $50 \%$. The maximum column diameter satisfying the salt solution boiling point (or safety) temperature limit under these conditions increases by $50 \%$ (from 34 inch to 51 inch diameter) when the cesium loading is decreased by $50 \%$. When the ambient temperature was changed from $45^{\circ} \mathrm{C}$ to $35^{\circ} \mathrm{C}$, the maximum temperatures expected for various column diameters (at $100 \%$ Cs loading) are shown in Figure 11. The maximum column diameters determined to maintain the temperature below the safety and operation limit criteria for these two ambient temperatures are compared in Table 8. A 33\% increase was observed in the column diameter required to satisfy (stay at or below) the operational limit at $35^{\circ} \mathrm{C}$ ambient temperature, while only a $6 \%$ increase was observed for the safety limit. These results bracket the range of temperatures expected under the upset scenario where active cooling is not functional.
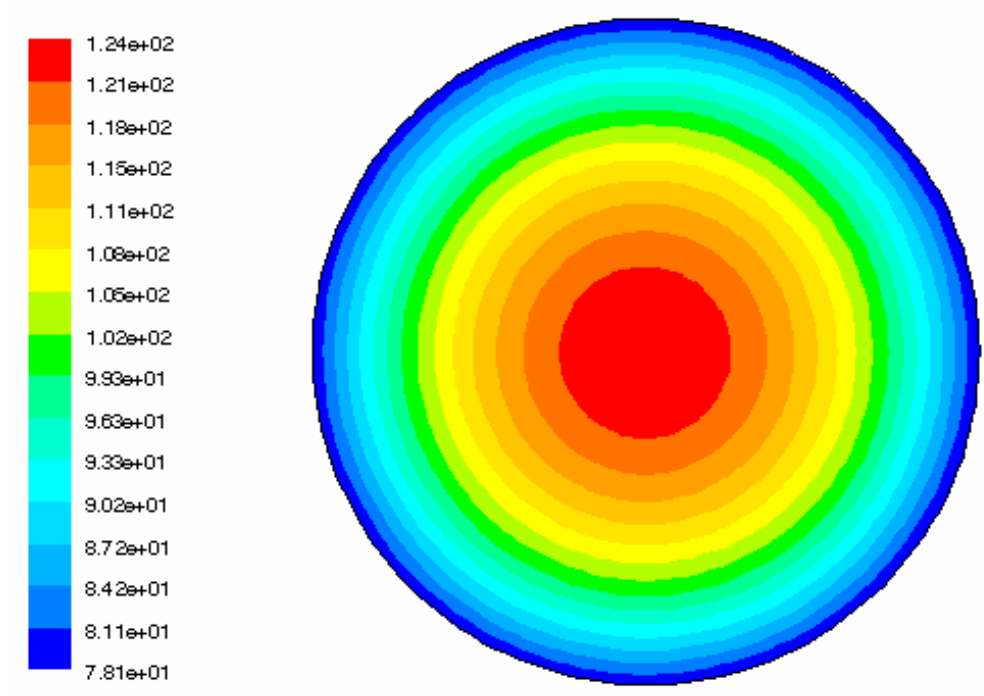

Contours of degc FLUENT 6.2 (2d, segregated, lam)

Figure 9. Temperature distributions for a 32 -in diameter RF column with $100 \%$ cesium loading (Case 1) 


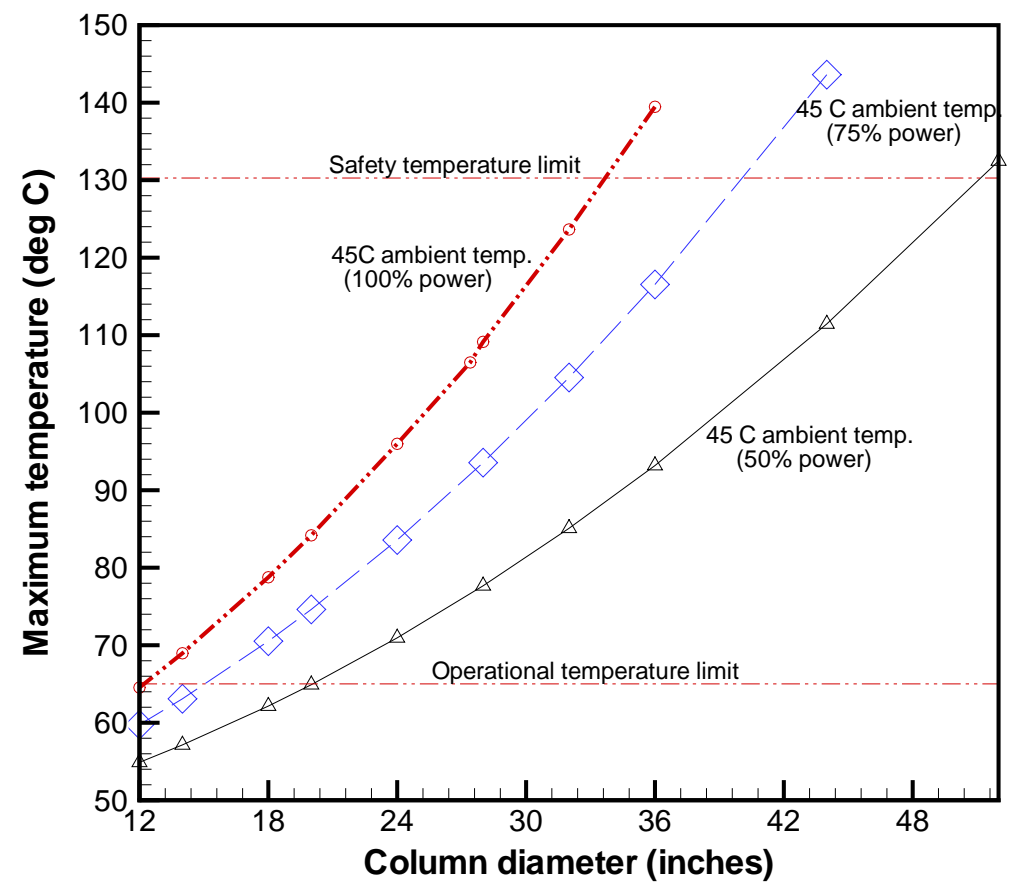

Figure 10. Max. column temperatures vs. column diameters under three different cesium loadings (Case 1, assumed Safety Temperature Limit = salt solution boiling point; assumed Operational Temperature Limit = assigned IX media limit)

Table 7. Quantitative comparison of the RF column sizes to satisfy the operation and safety limits under three different cesium loadings with $45^{\circ} \mathrm{C}$ ambient air temperature (Case 1)

\begin{tabular}{|c|c|c|}
\hline \multirow{2}{*}{$\begin{array}{c}\text { Cesium loading level } \\
\text { in RF column medium }\end{array}$} & \multicolumn{2}{|c|}{$\begin{array}{c}\text { Column diameter to satisfy the limit } \\
\text { (inches) }\end{array}$} \\
\cline { 2 - 3 } & $\begin{array}{c}\text { Operation limit } \\
\left(T_{\max }=65^{\circ} \mathrm{C}\right)\end{array}$ & $\begin{array}{c}\text { Safety limit } \\
\left(T_{\max }=130^{\circ} \mathrm{C}\right)\end{array}$ \\
\hline $100 \%$ load & 12 & 34 \\
\hline $75 \%$ load & 15 & 40 \\
\hline $50 \%$ load & 20 & 51 \\
\hline
\end{tabular}

Assumed Operational Limit = assigned media limit Assumed Safety Limit $=$ salt solution boiling point 


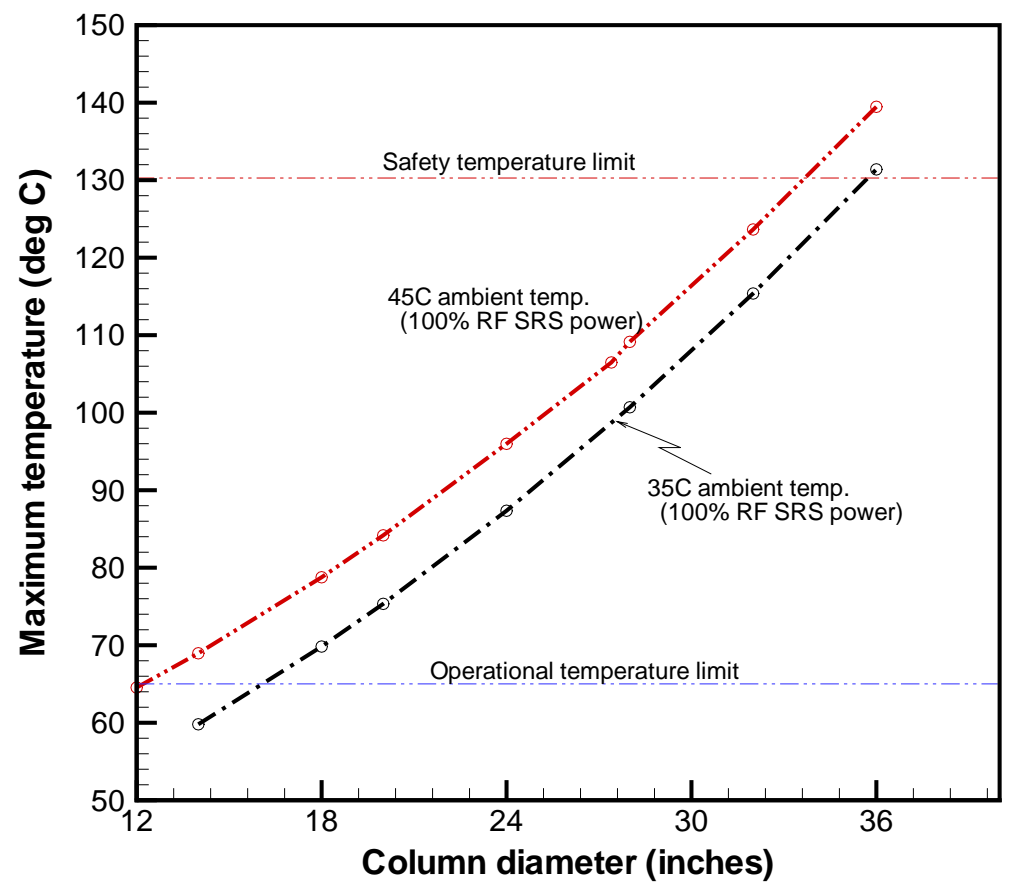

Figure 11. Comparison of max. column temperatures for two different ambient air temperatures, $35^{\circ} \mathrm{C}$ and $45^{\circ} \mathrm{C}$, at $100 \%$ cesium loading (Case 1 , assumed Safety Temperature Limit = salt solution boiling point; assumed Operational Temperature Limit = assigned IX media limit).

Table 8. Quantitative comparison of RF column sizes to satisfy the operation and safety limits under two different ambient air temperatures at $100 \%$ cesium loading (Case 1)

\begin{tabular}{|c|c|c|}
\hline \multirow{2}{*}{$\begin{array}{c}\text { Ambient air } \\
\text { temperature }\end{array}$} & \multicolumn{2}{|c|}{$\begin{array}{c}\text { Column diameter to satisfy the limit } \\
\text { (inches) }\end{array}$} \\
\cline { 2 - 3 } & $\begin{array}{c}\text { Operation limit } \\
\left(\mathrm{T}_{\max }=65^{\circ} \mathrm{C}\right)\end{array}$ & $\begin{array}{c}\text { Safety limit } \\
\left(\mathrm{T}_{\max }=130^{\circ} \mathrm{C}\right)\end{array}$ \\
\hline $45^{\circ} \mathrm{C}$ & 12 & 34 \\
\hline $35^{\circ} \mathrm{C}$ & 16 & 36 \\
\hline
\end{tabular}

Assumed Operational Limit = assigned media limit Assumed Safety Limit $=$ salt solution boiling point 


\subsection{RESULTS FOR CASE 2}

For Case 2 analysis, 100\% cesium loading with active cooling through the four external cooling tubes and no central cooling tube was considered to be the baseline condition. Other baseline conditions and parameters are provided in Table 1 and the modeling conditions for Case 2 are shown graphically in Figure 2. The calculated temperature distributions for a 28-in RF column with 100\% cesium loading under Case 2 are compared with those of Case 1 (which involved no active cooling) in Fig. 12. The impact of the cooling tubes can be seen in the square shape of the temperature profile shown in the lower figure. Active cooling through the outer tubes decreases the maximum steadystate temperature by $35^{\circ} \mathrm{C}$ (From 106 to $71^{\circ} \mathrm{C}$ ) for this diameter, but does not decrease the maximum temperature below the assumed media (or operational) temperature limit of $65^{\circ} \mathrm{C}$. Figure 13 compares the radial temperature distributions for the 28-in column between these two cases. Maximum column temperatures for various column diameters are presented for Case 1 and Case 2 in Fig. 14. The magnitude of separation between the two curves in Figure 14 is greater for lower diameter columns for two reasons. Heat transfer from smaller columns is more effective due to the larger ratio of column surface to bed volume (2/R) and the shorter heat transfer path length from the center to the wall boundary. Secondly, for this analysis, the size of the cooling tubes is held constant as the column diameter is varied. For smaller column diameters, this results in an increased ratio of the forced convective cooling area to the total exterior column wall surface area as shown in Fig. 15. Across the range of column diameters evaluated, this ratio varies from approximately $11 \%$ for larger columns to $41 \%$ for smaller columns. As expected for Case 2 with active cooling using four external cooling tubes, the column diameters which satisfy the safety and operation criteria are greater than those of Case 1 as shown in Table 9. The column diameter required for Case 2 to satisfy the safety limit is about $24 \%$ greater than that required for Case 1 . As shown in Table 9, the results indicate that a small reduction from the current baseline design diameter of 28 inches to 26 inches (see Case 2) results in a system that is expected to be maintained below the operational temperature limit with active cooling through the outer tubes. If the system is designed to maintain the columns below the assumed safety temperature limit, a column diameter as large as 34 inches (see Case 1) would maintain the column below the limit even without active cooling. Based on these results, it appears that removal of the central cooling tube is feasible for the RF column, although subsequent analysis revealed safety scenarios where the central cooling tube may be vital for temperature control - see Case 3 results. 

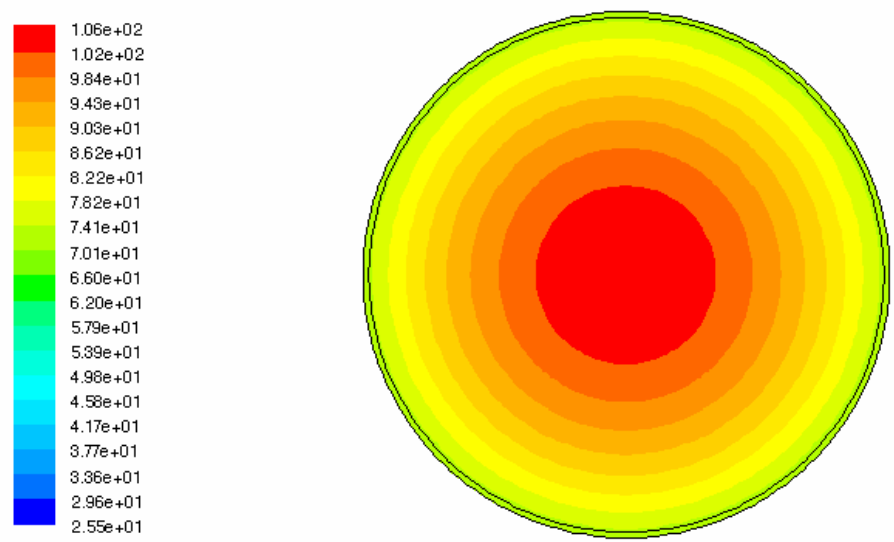

Contours of dege

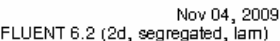

(Case $1, \mathrm{~T}_{\max }=106^{\circ} \mathrm{C}, \mathrm{T}_{\min }=73^{\circ} \mathrm{C}$ )
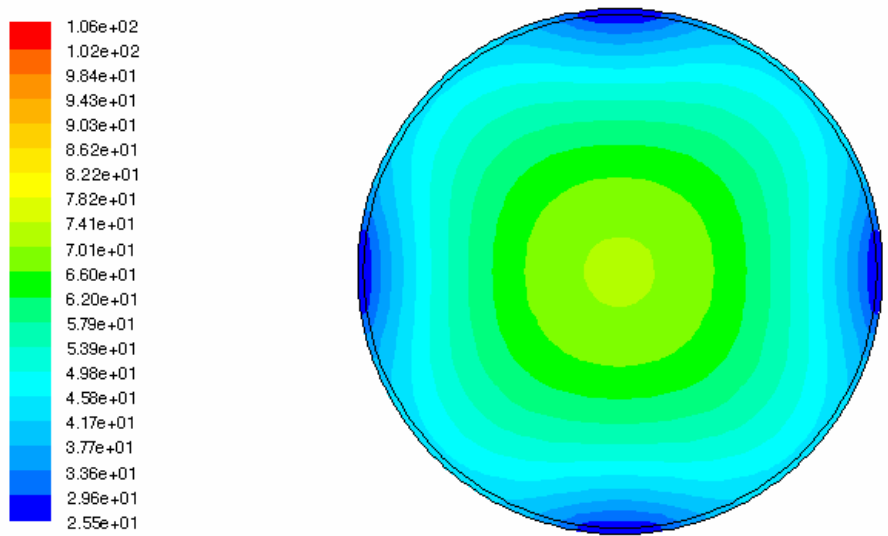

Contours of dego

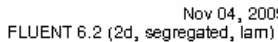

(Case $2, \mathrm{~T}_{\max }=71^{\circ} \mathrm{C}, \mathrm{T}_{\min }=26^{\circ} \mathrm{C}$ )

Figure 12. Comparison of temperature distributions for the 28in OD columns with 4 external cooling tubes (Case 2) and without cooling tubes (Case 1) 


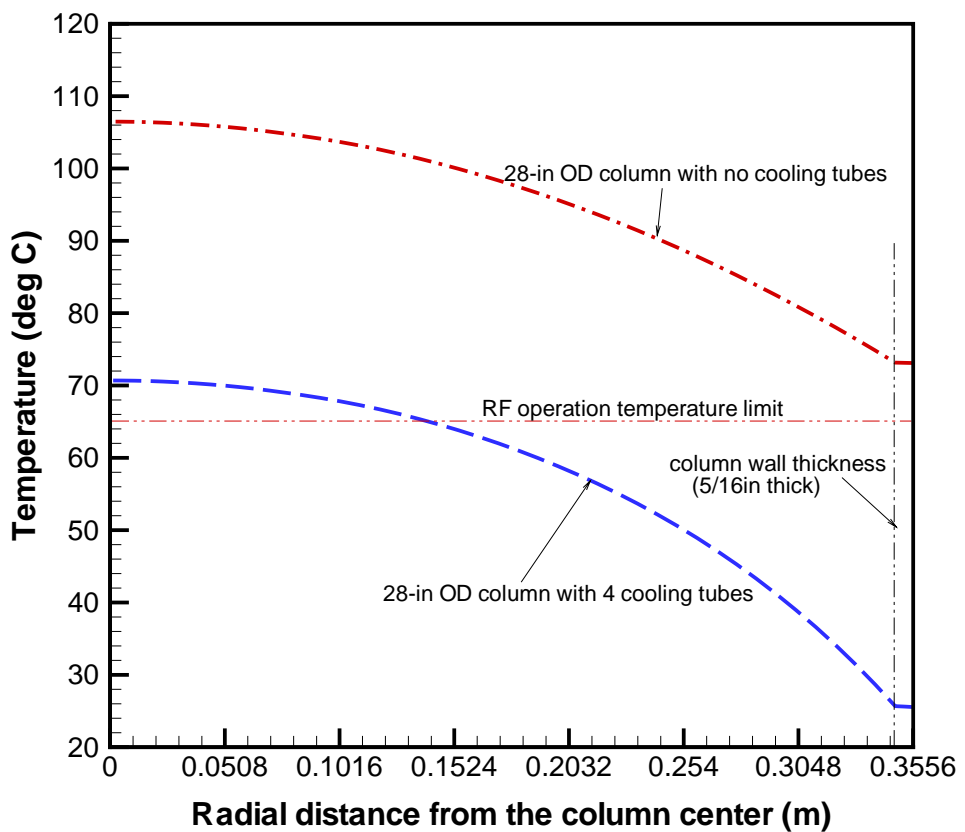

Figure 13. Comparison of radial temperature distributions for the 28-in RF column between Case 1 and Case 2 with 100\% Cs loading (Assumed Safety Temperature Limit $=$ salt solution boiling point; Assumed Operational Temperature Limit = assigned IX media limit)

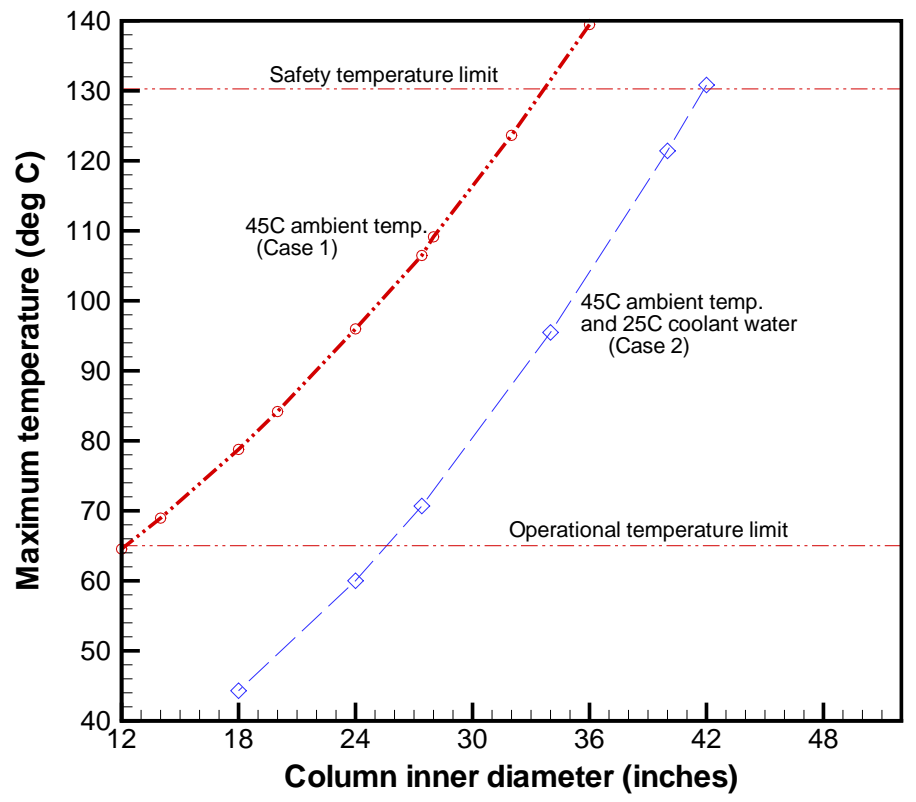

Figure 14. Comparison of maximum temperatures between Case 1 and Case 2 with 100\% Cs loading (Assumed Safety Temperature Limit = salt solution boiling point; Assumed Operational Temperature Limit = assigned IX media limit) 


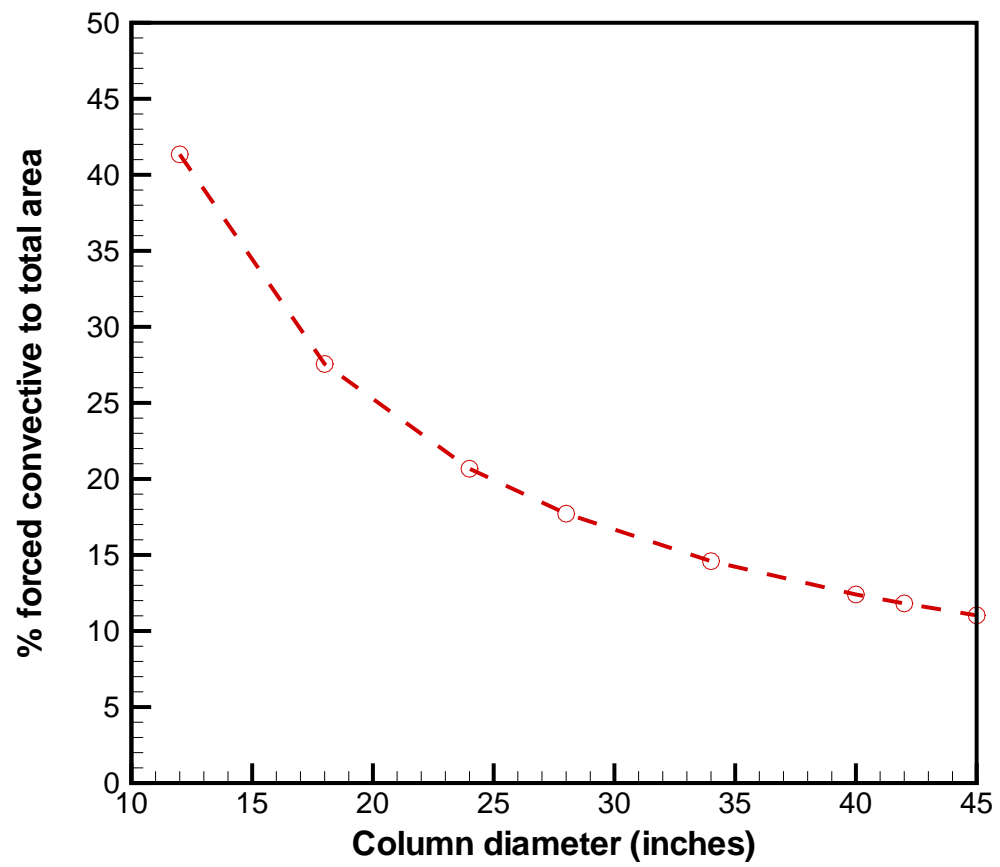

Figure 15. Percentage ratio of forced convective cooling area to total exterior column wall surface area versus column diameter

Table 9. Quantitative comparison of column sizes to satisfy the safety and operation limits between Case 1 and Case 2.

\begin{tabular}{|c|c|c|}
\hline \multirow{2}{*}{ Cases } & \multicolumn{2}{|c|}{ Column size (inches) } \\
\cline { 2 - 3 } & Operation limit $\left(65^{\circ} \mathrm{C}\right)$ & Safety limit $\left(130^{\circ} \mathrm{C}\right)$ \\
\hline Case 1 & 12 & 34 \\
\hline Case 2 & 26 & 42 \\
\hline
\end{tabular}

Assumed Operational Limit = assigned media limit

Assumed Safety Limit $=$ salt solution boiling point

\subsection{RESULTS FOR CASE 3}

For Case 3 analysis, a conservative approach was taken to estimate transient temperature profiles of dry RF columns filled with air as a result of a loss of fluid event due to the inadvertent drainage of salt solution from a fully loaded column. In this case, an air-filled column with 0.661 watts/liter volumetric loading with four active external cooling tubes and no central cooling tube was considered to be the baseline condition as shown in Fig. 2. Airfilled columns had not been considered in previous thermal analyses. 
Figure 16 compares transient maximum temperatures for six different column diameters under Case 3 conditions. For the 12 inch diameter column the maximum temperature never reaches $100{ }^{\circ} \mathrm{C}$, while with the 42 inch column the temperature exceeds $500{ }^{\circ} \mathrm{C}$ within 96 hours. The 14 inch column fully loaded with radioactive cesium was the largest diameter evaluated for which the maximum temperature never exceeded the assumed safety limit of $130^{\circ} \mathrm{C}$. Based on the results, a 15-inch column would be expected to just reach the safety temperature limit. With a 28 inch column the final steady-state temperature approaches 331 ${ }^{\circ} \mathrm{C}$. The times required to reach the operational and safety temperature limits for each diameter evaluated under Case 3 (air-filled) conditions are provided in Table 10. Since the operational limit is reached quickly and in the steep portion of the curve, the time required to reach this limit is nearly independent of column diameter within the range evaluated. For the 28 and 42 inch columns a similar response is observed for the safety limit as well. Clearly, for the air-filled column, the resin bed is expected to heat rapidly even with external cooling, and it may be necessary to include an emergency column liquid fill or elution system in the design to avoid excessive temperatures. Based on this analysis, the project may also want to consider testing to determine the consequences of allowing the ion exchange media to heat up to temperatures greater than $130{ }^{\circ} \mathrm{C}$. This assumed limit was based on the predicted salt solution boiling temperature. In the drained column scenario, boiling is not relevant and another temperature limit based perhaps on resin thermal decomposition reactions may be more appropriate.

Because this type of analysis can be highly sensitive to bed porosity, transient sensitivity studies were conducted for Case 3 using the minimum measured porosity for packed RF beds (36\%) and the theoretically highest (48\%) porosity for comparison to the baseline (43.2\%). These theoretical values are based on the same size of spherical particles [13,14]. Since varying the porosity also changes the effective bed density and therefore the total cesium loading in the column, the resin loadings for these evaluations were adjusted to account for this difference. Temperature distributions within the column using the nominal and the lowest bed porosities are provided in Fig. 17. Changing the porosity has a small impact on the temperature distribution. Figure 18 compares transient maximum temperatures for three different column porosities using the 28 -in column under the baseline Case 3 conditions. The results indicate that the maximum temperature decreases with higher porosity since a larger volume fraction of the column is occupied by air. The reduced cesium loading density associated with a higher porosity also serves to decrease the maximum temperature. Varying the porosity from the minimum value to the maximum theoretical value only resulted in a $14 \%$ decrease in the maximum column temperature after 96 hours. It therefore appears that for column diameters less than 28 inches, uncertainty in the bed porosity does not greatly impact the results. Radial temperature profiles within the bed for the 28 inch column for each porosity considered after 12 hours are provided in Fig. 19. This plot indicates the portion of the bed that exceeds the operational and safety temperature limits in each case. The times required to reach the operational and temperature limits for each porosity are provided in Table 11. In all cases the operational limit is reached within 3 hours and the safety limit is reached within 12 hours.

An additional transient calculation was conducted for the 28-in RF column under dry bed conditions (Case 3 ) using $50 \%$ of the maximum cesium loading. Figure 20 compares the trends calculated for the maximum column temperatures versus time for $50 \%$ and $100 \%$ Cs loading levels in the 28 inch column. The times required to reach the safety and operational temperature limits under Case 3 for the two cesium loading levels are provided in Table 12. Not surprisingly, reducing the cesium loading by $50 \%$ approximately doubles the time required to reach these limits and decreases the maximum steady-state temperature.

In order to evaluate the impact of the active cooling tubes for the baseline Case 3 condition, another calculation was conducted without any active cooling. This analysis 
was done for a column loaded to $50 \%$ cesium saturation. Results for the 28 inch column with and without active cooling are provided in Figure 21 . After 120 hours the maximum column temperature reached without active cooling $\left(211^{\circ} \mathrm{C}\right)$ is only $9 \%$ higher than the temperature reached with active cooling $\left(192^{\circ} \mathrm{C}\right)$. The results indicate that active cooling with 4 external cooling tubes is not highly effective at reducing the maximum column temperature since the active cooling surface area of the four tubes attached to the 28 -inch column corresponds to only about $18 \%$ of the external column wall surface as shown in Fig. 15. In both cases the operational temperature limit is reached within 6 hours and the safety temperature limit is reached within about 25 hours. Figure 22 compares two-dimensional temperature contours between the two cases (with and without active cooling) after 26 hours under the same cesium loading conditions. Radial temperature profiles between the forced and naturally cooled columns along the horizontal line from the column center to the wall region attached to one of the four cooling tubes (for the actively cooled case) are compared in Figure 23. Times required to reach the operational and temperature limits for each case are provided in Table 13.

Comparison of the maximum steady-state temperatures expected for fully-loaded 28 inch columns for each of the three cases evaluated are provided in Table 14. The results indicate that when a 28 -in column with four external cooling tubes is filled with waste supernate solution but with no liquid flow through the resin bed, the maximum column temperature is only $35{ }^{\circ} \mathrm{C}$ lower for the naturally-cooled column than for the actively cooled case (Case 1 versus Case 2). For the air-filled column the maximum temperature is very high $\left(331^{\circ} \mathrm{C}\right)$ due to the poor thermal characteristics of the gas phase. For the actively cooled cases the maximum temperature predicted is 4.7 times higher for the air-filled (Case 3) versus the water-filled column (Case 2). The dramatic difference in the maximum temperatures for these cases results from the different thermal conductivities of the two fluids.

Due to the extremely high maximum temperatures predicted for the air-filled column, additional analysis was conducted to determine the impact of a central cooling tube using a cesium-saturated, 28 inch column with the four external cooling pipes. A 6 inch diameter tube was added with assumed water flow through the tube of $12.5 \mathrm{gpm}$ at a fixed coolant temperature of $25^{\circ} \mathrm{C}$. Addition of a 6 -inch cooling tube results in a $4.6 \%$ reduction in the column volume and the corresponding heat load. As shown in Figs. 24 and 25 and in Table 15, the presence of the central cooling tube dramatically reduces the maximum predicted column temperature, the shape of the temperature distribution, and the time required to reach the assumed column safety limit. The maximum steadystate temperature is $197{ }^{\circ} \mathrm{C}$ lower for the column with the central tube and the temperature only slightly exceeded the safety limit of $130{ }^{\circ} \mathrm{C}$. In addition, the time required to reach the safety temperature limit increased from 12 to 35 hours with the addition of the central cooling tube. The modeling results demonstrate that although the lower cesium loading of spherical RF resin seems to allow for the removal of the central cooling tube under conditions where the resin bed remains immersed in liquid, the effectiveness of the central tube at cooling an air-filled column may prohibit this proposed design simplification. 


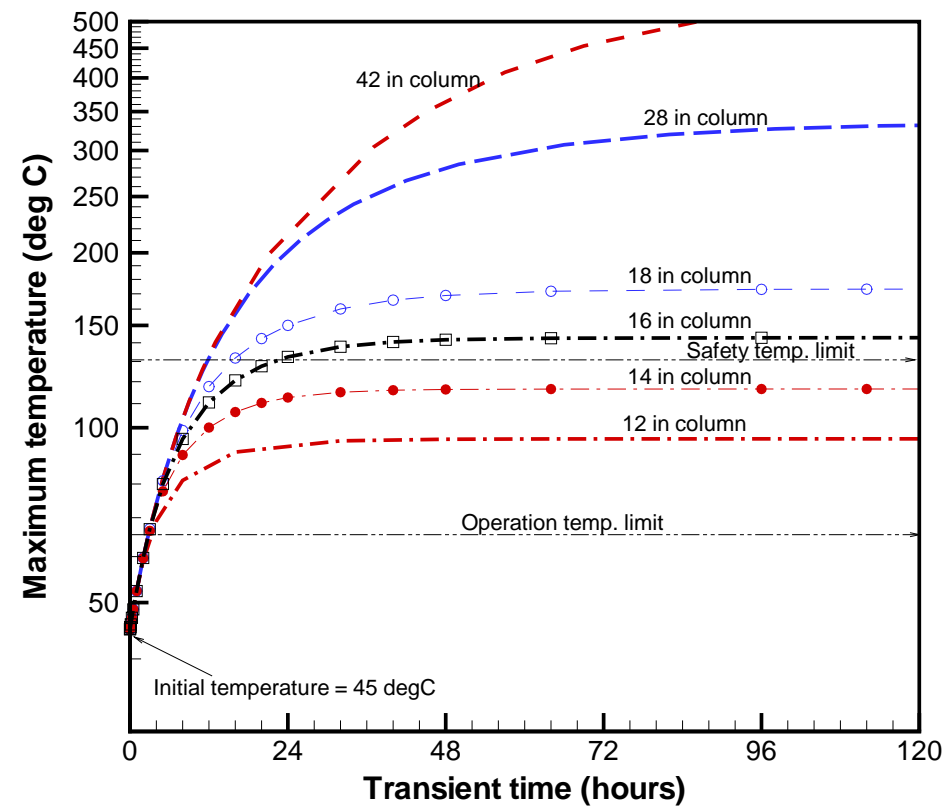

Figure 16. Comparison of transient maximum temperatures for three different column diameters under Case 3 (air-filled, water-cooled) conditions (Assumed Safety Temperature Limit $=130^{\circ} \mathrm{C}$; Assumed Operational Temperature Limit $=$ assigned IX media limit)

Table 10. Quantitative comparison of transient response times to reach the safety and operational temperature limits for various column diameters under Case 3.

\begin{tabular}{|c|c|c|}
\hline \multirow{2}{*}{$\begin{array}{c}\text { Column diameter } \\
\text { (inches) }\end{array}$} & \multicolumn{2}{|c|}{ Time (hours) } \\
\cline { 2 - 3 } & Operation limit $\left(65^{\circ} \mathrm{C}\right)$ & Safety limit $\left(130^{\circ} \mathrm{C}\right)$ \\
\hline 12 & 3.2 & $\begin{array}{c}\text { Never reached } \\
\left(\mathrm{T}_{\max }=96^{\circ} \mathrm{C}\right)\end{array}$ \\
\hline 14 & 2.8 & $\begin{array}{c}\text { Never reached } \\
\left(\mathrm{T}_{\max }=116.6^{\circ} \mathrm{C}\right)\end{array}$ \\
\hline 16 & 2.8 & 22.0 \\
\hline 18 & 2.8 & 15.6 \\
\hline 28 & 2.7 & 11.8 \\
\hline 42 & 2.7 & 11.6 \\
\hline
\end{tabular}

Assumed Operational Limit = assigned media limit Assumed Safety Limit $=130^{\circ} \mathrm{C}$ 

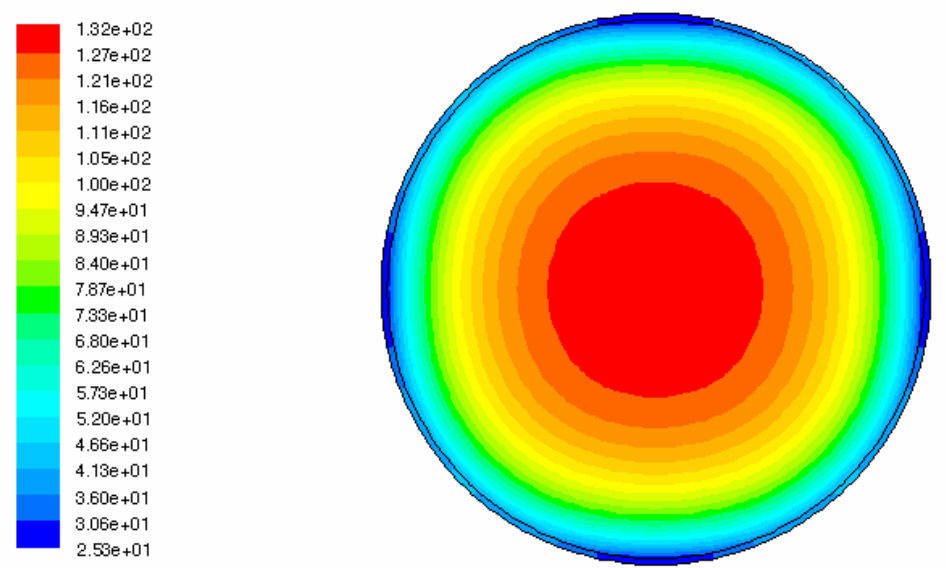

Contours of deg_c (Time $=4.3200 e+04)$

FLUENT 6.2 (2d, segregated, lam, unsteady)

(Case $3, T_{\max }=132^{\circ} \mathrm{C}, \mathrm{T}_{\min }=25^{\circ} \mathrm{C}, 43.2 \%$ bed porosity)
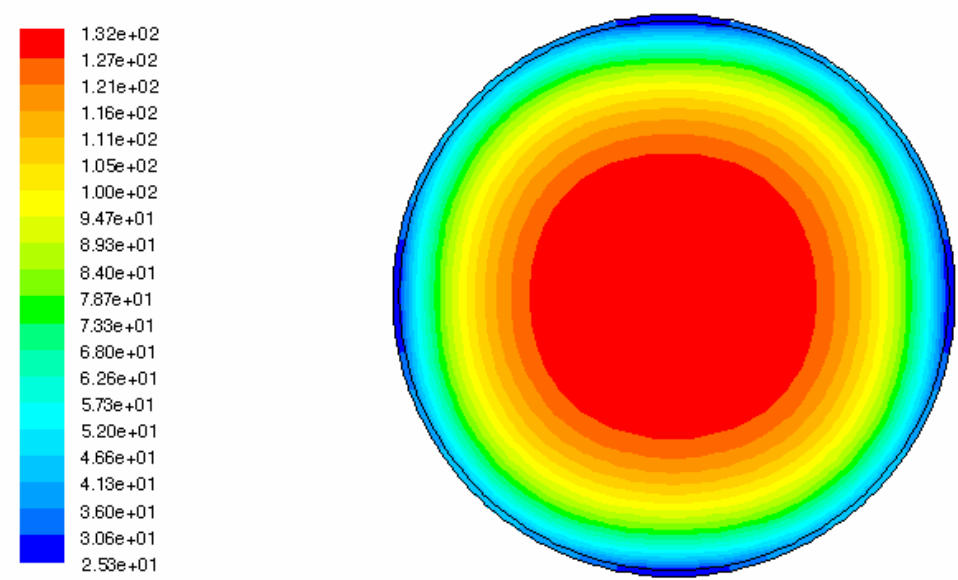

Contours of deg_c $($ Time $=4.3200 \mathrm{e}+04)$ Oct 21, 2009

(Case $3, \mathrm{~T}_{\max }=138^{\circ} \mathrm{C}, \mathrm{T}_{\min }=25^{\circ} \mathrm{C}, 36 \%$ bed porosity)

Figure 17. Comparison of temperature distributions for the dry columns with $43.2 \%$ and $36.0 \%$ porosities (Case 3 ) for the 28 in OD columns with 4 external cooling tubes at the transient time of 12 hours 


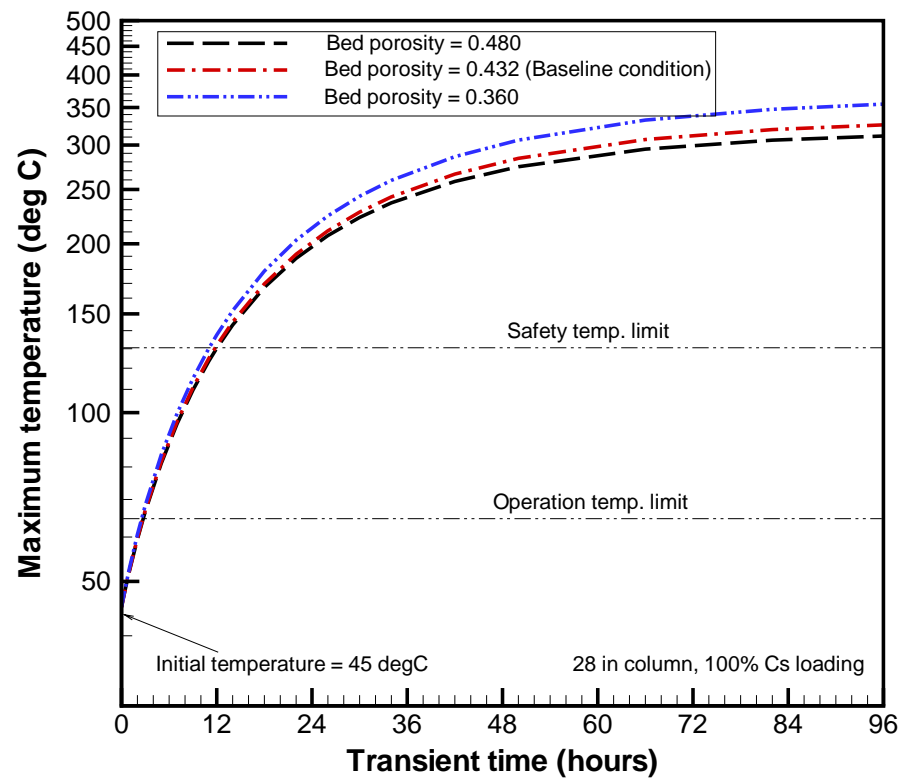

Figure 18. Comparison of transient maximum temperatures for three different column porosities under the 28-in column under Case 3 (air-filled, water cooled) conditions (Assumed Safety Temperature Limit $=130^{\circ} \mathrm{C}$; Assumed Operational Temperature Limit = assigned IX media limit).

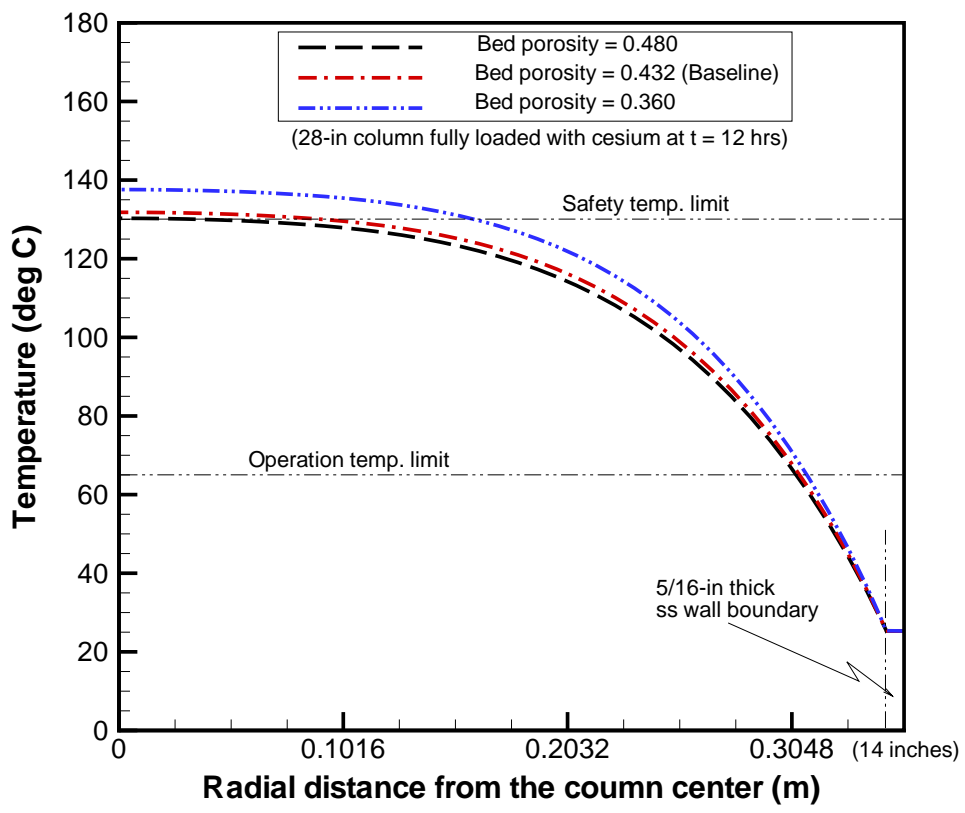

Figure 19. Comparison of radial temperature distributions for three different column porosities after 12 hours for the 28-in column under Case 3 conditions (Assumed Safety Temperature Limit $=130^{\circ} \mathrm{C}$; Assumed Operational Temperature Limit $=$ assigned IX media limit). 
Table 11. Quantitative comparison of transient response times to reach the safety and operational temperature limits for three different bed porosities under Case 3 conditions with a 28 inch column.

\begin{tabular}{|c|c|c|}
\hline \multirow{2}{*}{$\begin{array}{c}\text { Column bed } \\
\text { porosity* }\end{array}$} & \multicolumn{2}{|c|}{ Times (hours) } \\
\cline { 2 - 3 } & Operational limit $\left(65^{\circ} \mathrm{C}\right)$ & Safety limit $\left(130^{\circ} \mathrm{C}\right)$ \\
\hline $\begin{array}{c}0.432 \\
\text { (Baseline) }\end{array}$ & 2.7 & 11.8 \\
\hline 0.480 & 2.8 & 12.0 \\
\hline 0.360 & 2.6 & 11.0 \\
\hline
\end{tabular}

Note: Based on the bulk bed porosity (not including the porosity of the RF media.)

Assumed Operational Limit $=$ assigned media limit

Assumed Safety Limit $=130^{\circ} \mathrm{C}$

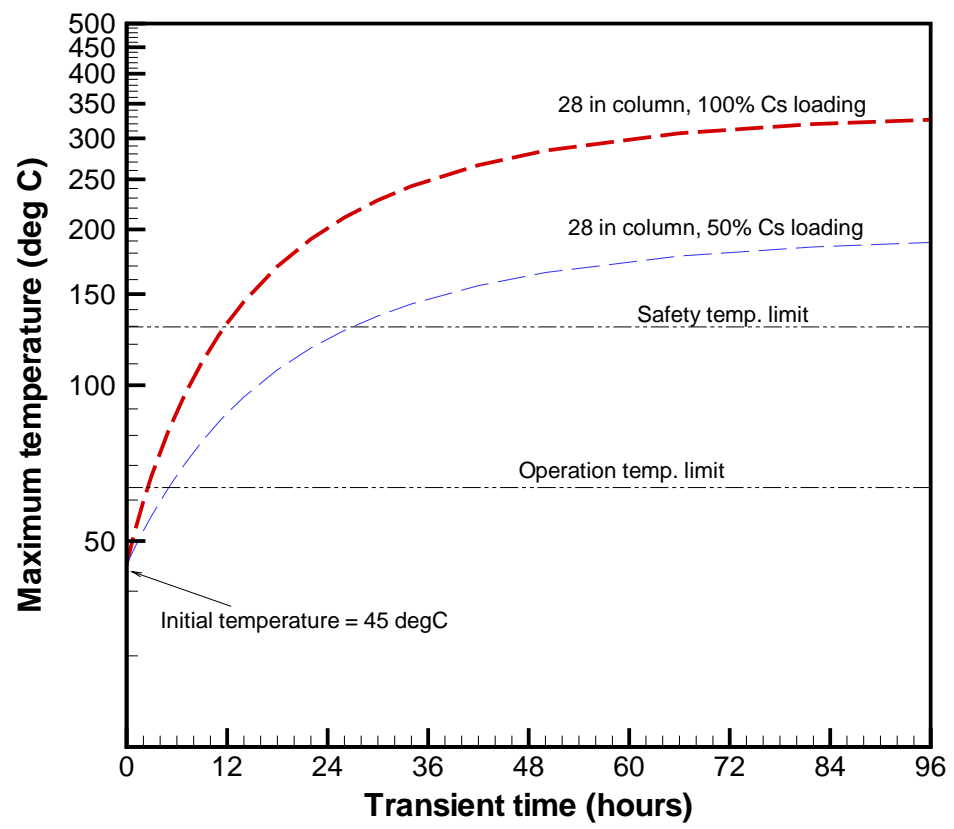

Figure 20. Comparison of maximum temperatures between $50 \%$ and $100 \%$ Cs loading levels for the 28 in column under Case 3 (air-filled, water-cooled) conditions (Assumed Safety Temperature Limit $=130^{\circ} \mathrm{C}$; Assumed Operational Temperature Limit = assigned IX media limit). 
Table 12. Quantitative comparison of Cs loading levels on transient response times for a 28 inch column to reach the safety and operational temperature limits under Case 3 conditions.

\begin{tabular}{|c|c|c|}
\hline \multirow{2}{*}{$\begin{array}{c}\text { Level of } \mathrm{Cs} \\
\text { loadings }\end{array}$} & Operational limit $\left(65^{\circ} \mathrm{C}\right)$ & Safety limit $\left(130^{\circ} \mathrm{C}\right)$ \\
\cline { 2 - 3 } & 3 & 12 \\
\hline Full loading & 5 & 27 \\
\hline $50 \%$ loading & 5 & \multicolumn{2}{|c|}{} \\
\hline
\end{tabular}

Assumed Operational Limit = assigned media limit Assumed Safety Limit $=130^{\circ} \mathrm{C}$

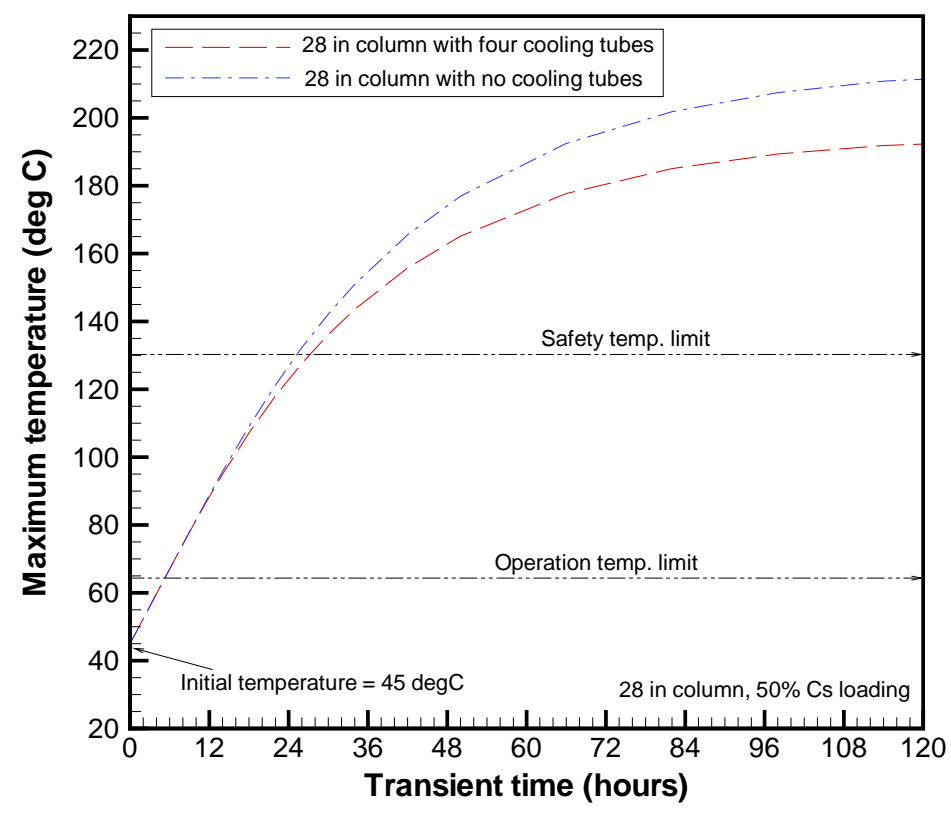

Figure 21. Comparison of transient maximum temperatures between the columns with and without external four cooling tubes under Case 3 conditions but with only $50 \%$ Cs loading (Assumed Safety Temperature Limit $=130^{\circ} \mathrm{C}$; Assumed Operational Temperature Limit = assigned IX media limit). 


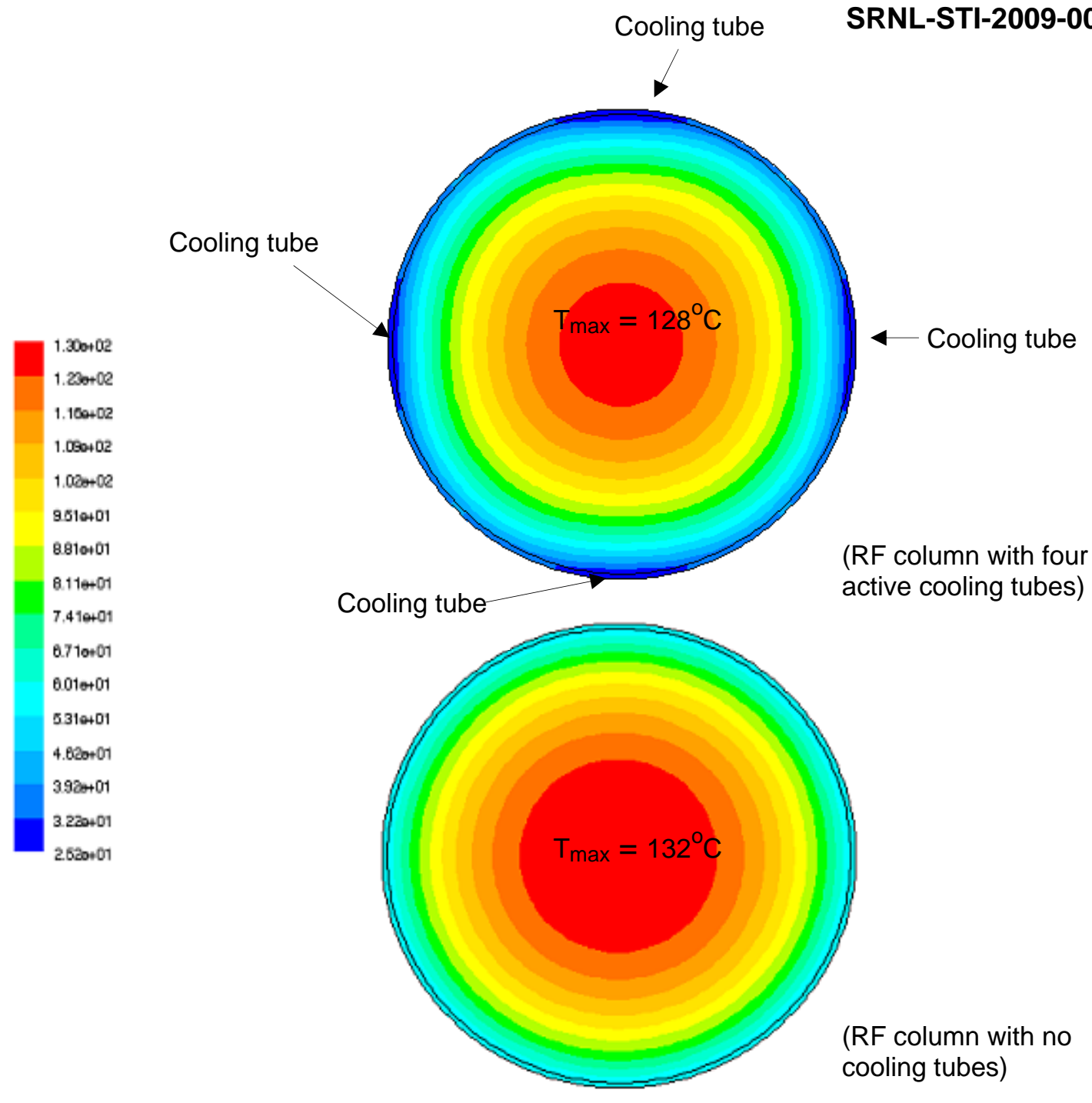

Figure 22. Comparison of radial temperature contours between the columns with and without four external cooling tubes at a transient time of 26 hours (Case 3 $50 \%$ Cs loading) 

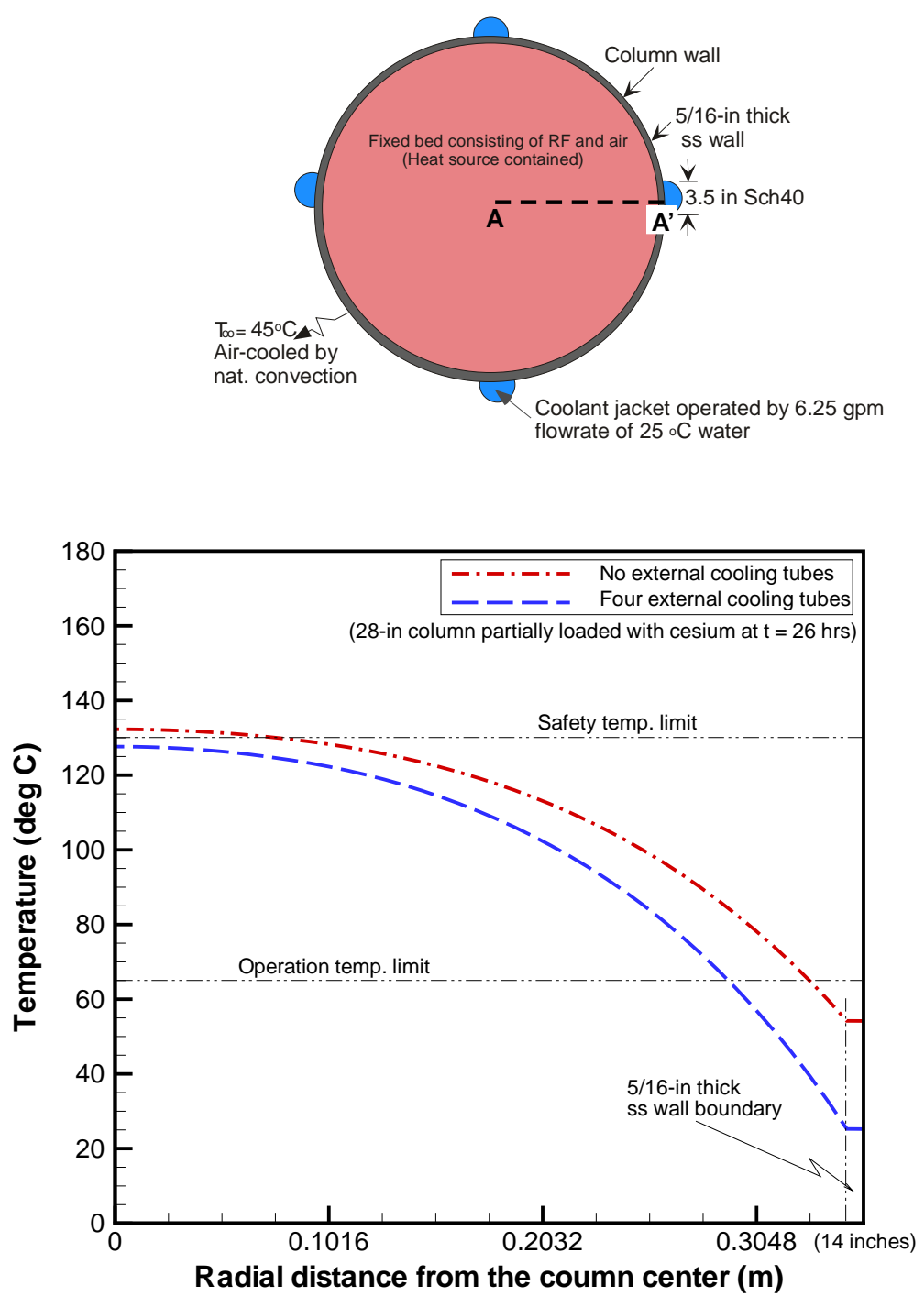

Figure 23. Comparison of radial temperature distributions along the line A-A' between the columns with and without four external cooling tubes at a transient time of 26 hours (Case 3, 50\% Cs loading, Assumed Safety Temperature Limit = $130^{\circ} \mathrm{C}$; Assumed Operational Temperature Limit = assigned IX media limit)) 
Table 13. Quantitative comparison of the impact of external cooling tubes on the transient response times to reach the safety and operational temperature limits under Case 3 conditions for the 28 inch column with $50 \%$ loading.

\begin{tabular}{|c|c|c|}
\hline \multirow{2}{*}{$\begin{array}{c}\text { Engineered external } \\
\text { cooling system }\end{array}$} & \multicolumn{2}{|c|}{ Time (hours) } \\
\cline { 2 - 3 } & Operational limit $\left(65^{\circ} \mathrm{C}\right)$ & Safety limit $\left(130^{\circ} \mathrm{C}\right)$ \\
\hline $\begin{array}{c}\text { Four active ext. } \\
\text { cooling tubes }\end{array}$ & 5 & 27 \\
\hline $\begin{array}{c}\text { No external cooling } \\
\text { tubes }\end{array}$ & 5 & 25 \\
\hline
\end{tabular}

Note: The thermal penetration time from the column center to the wall boundary due to thermal diffusion is approximately 7 hours.

Assumed Operational Limit $=$ assigned media limit Assumed Safety Limit $=130^{\circ} \mathrm{C}$

Table 14. Quantitative comparison of maximum steady-state temperature for all three cases with 28-in fully-loaded column.

\begin{tabular}{|c|c|c|c|}
\hline Cases & $\begin{array}{c}\text { Column } \\
\text { conditions }\end{array}$ & Cooling mechanism & $\begin{array}{c}\text { Max. steady-state temp. } \\
\left({ }^{\circ} \mathbf{C}\right)\end{array}$ \\
\hline Case 1 & $\begin{array}{c}\text { Wet } \\
\text { column }\end{array}$ & Natural convection only & 106 \\
\hline Case 2 & $\begin{array}{c}\text { Wet } \\
\text { column }\end{array}$ & $\begin{array}{c}\text { Nat. convection with four } \\
\text { ext. active cooling tubes }\end{array}$ & 71 \\
\hline Case 3 & $\begin{array}{c}\text { Dry } \\
\text { column }\end{array}$ & $\begin{array}{c}\text { Nat. convection with four } \\
\text { ext. active cooling tubes }\end{array}$ & 331 \\
\hline
\end{tabular}



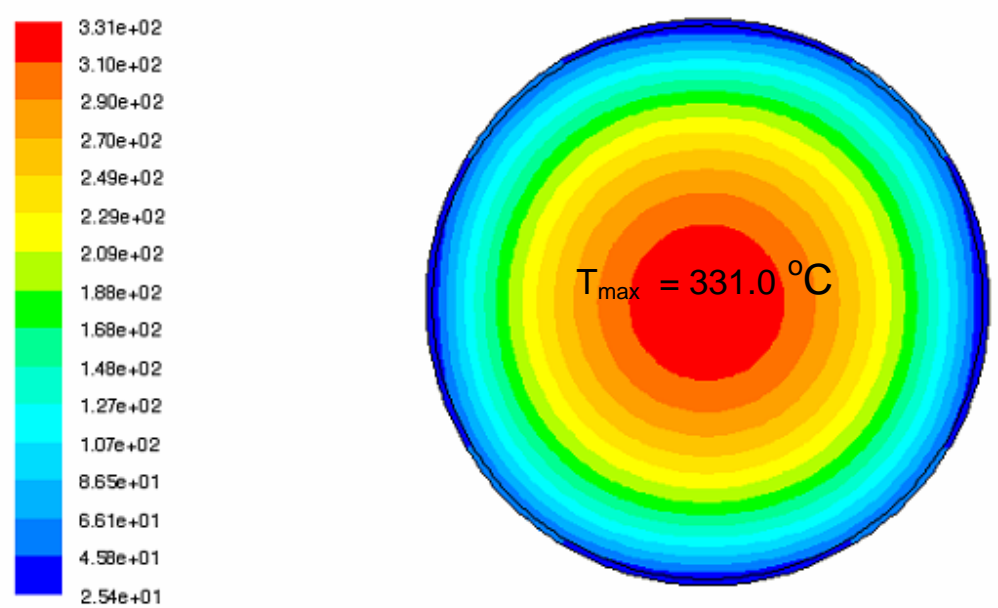

(28-in column baseline design)

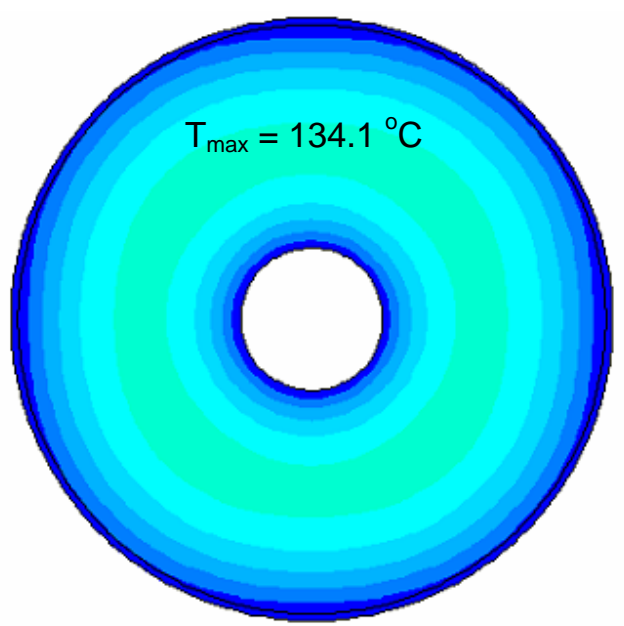

(28-in column baseline design with 6-in central cooling tube)

Figure 24. Comparison of steady-state temperature contours between the 28-in baseline columns with and without 6 -in central cooling tube under the Case3 conditions 


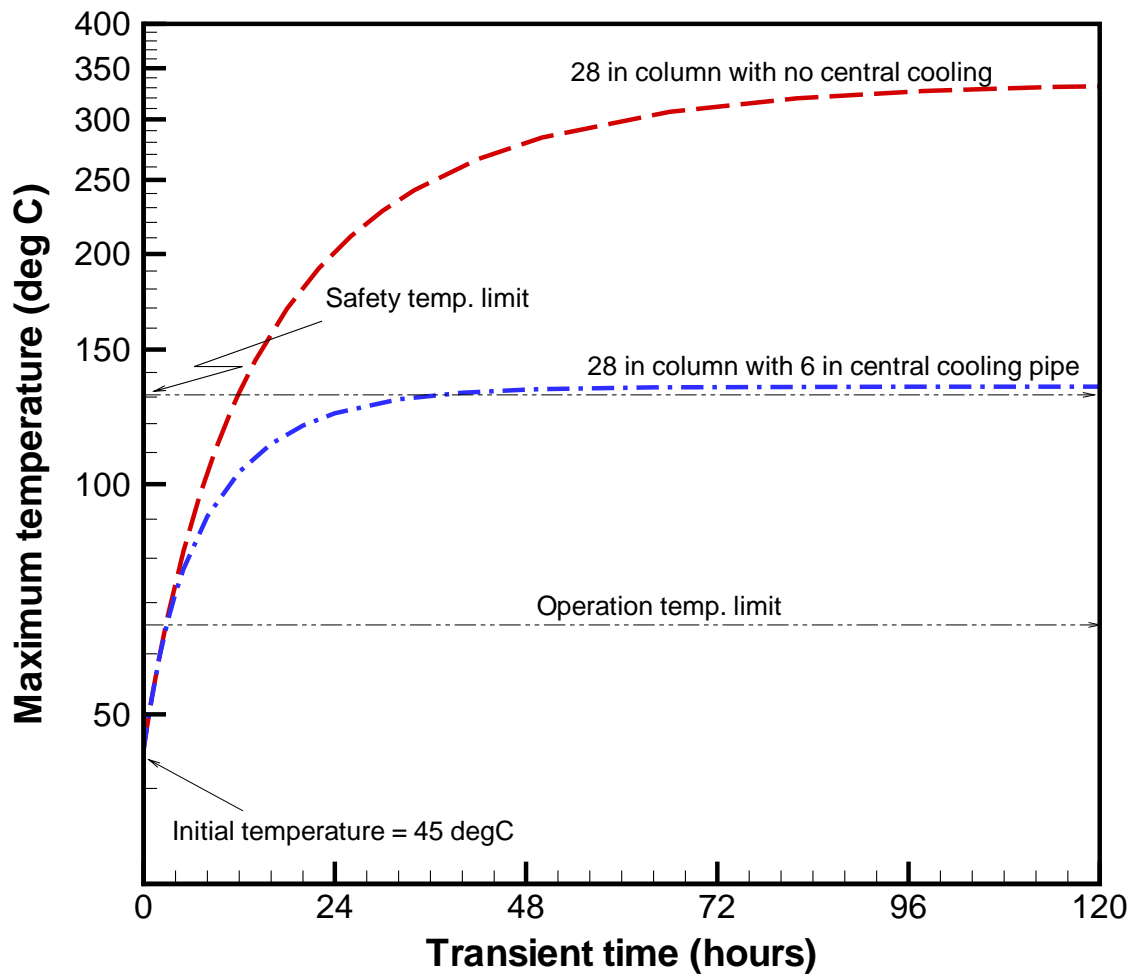

Figure 25. Comparison of transient max. temperatures between the columns with and without 6-in central cooling pipe under the 28-in fully-loaded dry column with four external cooling tubes (Assumed Safety Temperature Limit $=130^{\circ} \mathrm{C}$; Assumed Operational Temperature Limit = assigned IX media limit)

Table 15. Quantitative comparison of the impact of 6-in central cooling tube on the transient response times to reach the safety and operational temperature limits under Case 3 conditions for the 28 inch column with 100\% loading.

\begin{tabular}{|c|c|c|c|}
\hline \multirow{2}{*}{$\begin{array}{c}\text { Engineered cooling } \\
\text { systems }\end{array}$} & \multicolumn{2}{|c|}{$\begin{array}{c}\text { Time to reach max. temperatures } \\
\text { (hours) }\end{array}$} & $\begin{array}{c}\text { Steady-state } \\
\text { max. temperature } \\
\left({ }^{\circ} \mathrm{C}\right)\end{array}$ \\
\cline { 2 - 4 } & $\begin{array}{c}\text { Operational limit } \\
\left(65^{\circ} \mathrm{C}\right)\end{array}$ & $\begin{array}{c}\text { Safety limit } \\
\left(130^{\circ} \mathrm{C}\right)\end{array}$ & 331.3 \\
\hline $\begin{array}{c}\text { Only four external } \\
\text { cooling tubes }\end{array}$ & 2.7 & 11.8 & 134.1 \\
\hline $\begin{array}{c}\text { 6-in central tube with } \\
\text { four ext. cooling tubes }\end{array}$ & 2.9 & 34.8 & \\
\hline
\end{tabular}

Assumed Operational Limit = assigned media limit Assumed Safety Limit $=130^{\circ} \mathrm{C}$ 


\subsection{CONCLUSIONS AND SUMMARY}

Two-dimensional models have been developed to simulate the thermal performance of the RF column baseline design fully loaded with radioactive cesium and to calculate temperature distributions and maximum temperatures across the column during SCIX upset conditions. The current modeling analysis focuses on SCIX application at Hanford where RF is likely the preferred media. For most calculations the design did not include a central cooling tube inside the column, but did include the outer cooling tubes. All calculations assumed that the fluid within the column is stagnant. The current full-scale design for the SCIX system does include the central cooling tube, and one objective of these calculations was to examine its elimination to simplify the design. The baseline models were benchmarked against theoretical results.

The modeling calculations were conducted using conservative, bounding estimates for key parameters such that the results would provide the maximum temperatures achievable under the design configurations. A feed composition and cesium loading were assumed which were known to be considerably higher than would typically be observed at Hanford. In order to evaluate the impact of this potentially highly conservative assumption, fractionally-reduced loading cases were also considered. Steady state and transient modeling calculations were performed for three different conditions involving packed beds of RF resin which were saturated in cesium and immersed in waste supernate, as well as the case where the same, saturated bed had been inadvertently drained of liquid. In all cases, convection effects resulting from thermally induced motions of the fluid were assumed to be negligible to provide a conservative estimate of the maximum column temperatures. The column for Case 1 was cooled only by natural convection at the surface of the column, and the wet and drained columns for Cases 2 and 3 were cooled by both forced convective cooling through four external cooling tubes and natural convection at the remaining column wall sections. A constant ambient air temperature of $45^{\circ} \mathrm{C}$ was assumed for most cases. A "safety temperature limit" of $130^{\circ} \mathrm{C}$ was assumed based on the calculated salt solution boiling point. An "operational temperature limit" of $65^{\circ} \mathrm{C}$ was assumed based on the perceived temperature limit for the ion exchange media.

The main results are summarized as follows:

- Without any engineered cooling systems (Case 1) and assuming columns suspended in unventilated ambient air at $45^{\circ} \mathrm{C}$, the maximum diameter of the fullyloaded column expected to maintain the temperature below the assumed media and safety limits is 12 inches. In this case the maximum column diameter required to satisfy only the safety limit is 34 inches.

- For an RF column under Case 2 conditions with active cooling through four outer tubes and $45{ }^{\circ} \mathrm{C}$ ambient external air, the maximum column diameter expected to maintain the temperature below the assumed media and safety limits is 26 inches.

- Modeling analysis was conducted to predict the maximum column temperatures for the previously unevaluated accident scenario involving inadvertent drainage of a cesium-saturated column (Case 3). As expected, much higher maximum temperatures were observed in this case due to the poor heat transfer properties of air, compared to those of liquid. The results indicate that the maximum temperature within a 28 inch diameter RF column exceeds $250^{\circ} \mathrm{C}$ within 2 days, while the maximum temperature of a 12 inch column never reaches $100^{\circ} \mathrm{C}$. 
- The maximum column temperature decreases with higher porosity since a larger volume fraction of the column is air and because there is a smaller amount of cesium present within the column. Varying the porosity from the minimum value to the maximum theoretical value only resulted in a $14 \%$ decrease in the maximum column temperature after 96 hours with a 28 inch column under Case 3 conditions (air-filled, water cooled through 4 external tubes). In all cases the operational limit was reached within 3 hours and the safety limit was reached within 12 hours. The results indicate that the maximum column temperature is not highly impacted by porosity uncertainties.

- When cesium loading levels for the 28-in RF column under dry bed conditions are reduced from $100 \%$ to $50 \%$, the time required to reach the safety and operational temperature limits is approximately doubled.

- The impact of the active external cooling tubes for the air filled column is small because the active cooling area ratio of the four external tubes to external column wall surface is only about $18 \%$ for 28 -in column, and the air medium of the drained column has low thermal conductivity. Under Case 3 conditions with $50 \%$ cesium saturation, it was shown that after 120 hours, the maximum column temperature predicted without active cooling $\left(211^{\circ} \mathrm{C}\right)$ was only $9 \%$ higher than the temperature reached with active cooling $\left(192^{\circ} \mathrm{C}\right)$. The results indicate that the external engineered cooling system is not highly effective at reducing the maximum column temperature for the air-filled column.

- When a 6 inch diameter cooling tube was inserted at the center of a 28-in air-filled column, the presence of the central cooling tube dramatically decreased the maximum predicted column temperature (from $331^{\circ} \mathrm{C}$ to $134^{\circ} \mathrm{C}$ ). The shape of the temperature distribution also changed and the time required to reach the column safety limit increased from 12 to 35 hours.

- The modeling results demonstrate that although the lower cesium loading of spherical RF resin immersed in liquid seems to allow for the removal of the central cooling tube, the effectiveness of the central tube at cooling an air-filled column may prohibit this proposed design simplification.

\subsection{REFERENCES}

1. King, W. D., Duffey, C. E., Malene. S. H., 2004. "Determination of Cesium $\left(\mathrm{Cs}^{+}\right)$ Adsorption Kinetics and Equilibrium Isotherms from Hanford Waste Simulants using Resorcinol-Formaldehyde Resins (U)" WSRC-TR-2003-00574, Rev. 0, March 2004.

2. S. Y. Lee, "Task Plan For Thermal Modeling of Ion Exchange Columns with Spherical RF Resin", Savannah River National Laboratory, SRNL-TR-200900270, Rev. 0, July 2009.

3. S. Y. Lee, "Heat Transfer Analysis for Fixed CST and RF columns, Savannah River National Laboratory, WSRC-STI-2007-00345, October 2007.

4. F. G. Smith, III, "Modeling of Ion-Exchange for Cesium Removal from Dissolved Saltcake in SRS Tanks 1-3, 37 and 41", WSRC-STI-2007-00315, June 2007. 
5. W. D. King, F. G. Smith, S. Y. Lee, D. J. McCabe, and T. Punch, "Comparisons of RF and CST Media for Cesium Removal by In-Tank Column Processing", $15^{\text {th }}$ Symposium on Separation Science and Technology, Gatlinburg, TN, October 2007.

6. F. G. Smith, III, S. Y. Lee, W. D. King, D. J. McCabe, "Comparisons of Crystalline Silicotitanate and Resorcinol Formaldehyde Media for Cesium Removal by Intank Column Processing", Separation Science and Technology, vol. 43, pp. 2929, 2008.

7. R. Krupiczka, "Analysis of Thermal Conductivity in Granular Materials", International Chemical Engineering, Vol. 7, No. 1, pp. 122-144 (1967).

8. Fluent $^{T M}$, Ansys, Inc., 2008.

9. S. E. Aleman, G. P. Flach, L. L. Hamm, S. Y. Lee, and F. G. Smith, III, 1993, "FLOWTRAN-TF Code Software Design (U)", WSRC-TR-92-532, Savannah River National Laboratory, Westinghouse Savannah River Company, February 1993.

10. W. M. Kays and M. E. Crawford, Convective Heat and Mass Transfer, Second Edition, McGraw-Hill Book Company, New York (1980).

11. C. Y. Warner and V. S. Arpaci, "An Experimental Investigation of Turbulent Natural Convection in Air at Low Pressure along a Vertical Heated Flat Plate", International Journal of Heat and Mass Transfer, Vol. 11, pp. 397-406 (1968).

12. F. W. Dittus and L. M. E. Boelter, Engineering Publication vol. 2, pp. 443, University of California (1930).

13. V. E. Schrock, C. H. Wang, S. Revankar, L. H. Wei, and S. Y. Lee, "Steam-Water Flooding in Debris Beds and Its Role in Dryout", Electric Power Research Institute, EPRI NP-3858, March 1985.

14. S. Y. Lee, "Two-Phase Flow and Heat transfer in Porous Media", MS Thesis, Massachusetts Inst. of Technology, 1983.

15. J. P. Holman, Heat Transfer, $4^{\text {th }}$ edition, McGraw-Hill Book Company, New York (1976).

16. R. H. Perry and C. H. Chilton, Chemical Engineers' Handbook, McGrawHill Book Company, New York (1973). 